\title{
Evaluation of mechanical, thermal and water absorption behaviors of Polyalthia longifolia seed reinforced vinyl ester composites
}
B. Stalin ${ }^{1, ~ *}$, N. Nagaprasad ${ }^{2}$, V. Vignesh ${ }^{3}$, M. Ravichandran ${ }^{4}$, Nagarajan Rajini $^{5, *}$, Sikiru Oluwarotimi Ismail ${ }^{6}$, Faruq Mohammad ${ }^{7}$
${ }^{1}$ Department of Mechanical Engineering, Anna University, Regional Campus Madurai, Madurai- 625 019, Tamil Nadu, India.
${ }^{2}$ Department of Mechanical Engineering, ULTRA College of Engineering and Technology, Madurai- 625107, Tamil Nadu, India.

${ }^{3}$ Department of Mechanical Engineering, Sethu Institute of Technology, Pulloor, Kariapatti 2 626 115, Tamil Nadu, India.
${ }^{4}$ Department of Mechanical Engineering, K. Ramakrishnan College of Engineering, Samayapuram, Tiruchirappalli- 621 112, Tamil Nadu, India. ${ }^{5}$ Department of Mechanical Engineering, Kalasalingam University, Krishnankoil, Virudhunagar- 626 126, Tamil Nadu, India.
${ }^{6}$ Department of Engineering, Centre for Engineering Research, School of Engineering and Computer Science, University of Hertfordshire, Hatfield, AL10 9AB, England, UK. ${ }^{7}$ Department of Chemistry, College of Science, King Saud University, Riyadh, 11451, Kingdom of Saudi Arabia.

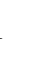




\section{Abstract}

This study presents a novel utilization of biomass solid waste, named Polyalthia longifolia (Mast tree) seed as a reinforcement in a composite, using a compression molding technique. An attempt was made to reinforce vinyl ester matrix (VE) with Polyalthia longifolia seed filler (PLSF), ranging from 5 to $50 \mathrm{wt} \%$ loadings. Mechanical properties of the fabricated Polyalthia longifolia seed filler/vinyl ester (PLSF-VE) composite samples were tested and analyzed. The results showed that the PLSF-VE composite exhibited optimum mechanical properties at 25 $\%$ wt of filler loading; ultimate tensile strength and modulus were approximately $32.50 \mathrm{MPa}$ and 1.23 GPa, respectively. The ultimate flexural, impact strengths and hardness were observed around $125 \mathrm{MPa}, 31.09 \mathrm{~kJ} / \mathrm{m}^{2}$ and 36.50 , respectively. The heat deflection test and thermo-gravimetric analysis depicted that the PLSF-VE composites withstood up to $66{ }^{\circ} \mathrm{C}$ and $430{ }^{\circ} \mathrm{C}$, respectively. Furthermore, the PLSF and its various composite samples were studied, using energy-dispersive X-ray (EDX), X-ray diffraction (XRD), Fourier transform infrared spectroscopy (FTIR) and scanning electron microscope (SEM).

Keywords: Polyalthia longifolia seed filler, Vinyl ester, Compression molding, Properties, Characterization. received much attention, as they are environmentally friendly. Acceptably, polymers are reinforced with fibers or fillers to produce materials that are suitable for industrial requirements. Polyalthia longifolia tree is mostly used for manufacturing small articles, such as pencil boxes, lightweight trunk and various herbal preparations. The lightweight trunk was used earlier in making masts for sailing ships; therefore, its name becomes Mast tree. In a 
longifolia seeds was explored. The rationale behind making an attempt to use this plant material include their natural renewability, biodegradability, sustainability as well as non-toxicity. Thus, it becomes an environmental friendly reinforcing material with respect to its harmless processing and disposal. The various influences of nutshells from pistachio, almond, walnut and pecan on polymer composites have been reported (Dixit, Mishra, Pal, Rana, \& Upreti, 2014; Rao \& Rehman, 2012; Sánchez-Acosta et al., 2019; Sutivisedsak et al., 2012). Today environmentalists and researchers have strived hard to reduce the industrial wastes accumulated over the surface of the earth. Several researchers use industrial wastes to fabricate composite materials and reduce environmental pollution, caused by inexpensive hazardous material from industries. By using the non-toxic materials, accumulated waste substances on earth will be reduced. Therefore, living safely on earthly will be more supported (Richard et al., 2019; Vigneshwaran et al., 2019). In a particulate-filled polymer composite, the mechanical strength strictly depends on particle size, shape, dispersion of particle into the matrix of the composite and also fiber or particle-polymer matrix interfacial bonding (Richard et al., 2019). The mechanical behaviors of a polymer matrix have been enhanced by incorporating several industrial wastes, including fly ash, sewage sludge ash and silicon carbide micro-particles to the matrix used (Erkliğ, Alsaadi, \& Bulut, 2016). Clay, as an organic filler, has also been added to polymer composites to improve the mechanical behaviors of the polymer composites, with a high specific surface area (Bensalah et al., 2017). Erdogan and Huner (2018) investigated the reinforcing influence of pinewood sawdust, black rice husk powder and walnut shell flour on polypropylene. A commonly used coupling agent, known as maleic anhydride polypropylene (MAPP) was used to study the strength of the composite. The results depicted that the mechanical behaviors of the composite decreased after adding the aforementioned reinforcements. However, adding MAPP increased both mechanical and 
powder/poly (lactic acid) composites. Their results indicated that the maximum tensile strength obtained was 51.3 MPa; better mechanical strength up to $0.5 \mathrm{wt} \%$ of filler loading and then decreased because the walnut shell powder agglomerated more within the poly (lactic acid) matrix. Vaisakh et al. (2016) studied the micro and modified nano-size of $\mathrm{SiO}_{2} / \mathrm{Al}_{2} \mathrm{O}_{3}$ reinforced epoxy composites. Their results showed that mixed-matrix $\mathrm{SiO}_{2} / \mathrm{Al}_{2} \mathrm{O}_{3}$ ceramic filler matrix produced high compressive strength of $196 \mathrm{MPa}$ and flexural modulus of 7.6 GPa. The nano-modified mixed-matrix $\mathrm{SiO}_{2} / \mathrm{Al}_{2} \mathrm{O}_{3}$ showed a controlled rate of wear as well as reduction in friction coefficient. Various fillers of biochar particles derived from rice husk (Richard, Rajadurai, \& Manikandan, 2016), fishbone (Abhishek et al., 2018), hemp hurds, alfalfa, and grape stem (Battegazzore, Noori, \& Frache, 2019), lignocellulosic wood (Kumar, Kumar, \& Bhowmik, 2018), thyme herbs (Montanes, Garcia-Sanoguera, Segui, Fenollar, \& Boronat, 2018), rice husk ash and siliceous earth-Sillitin Z 86 (Pongdong, Kummerlöwe, Vennemann, Thitithammawong, \& Nakason, 2018) have been added to various polymer matrices to reduce the materials (polymers) cost, enhance important properties of the resultant composites, such as mechanical, dimensional and thermal stability.

This work explored the possibility of using Polyalthia longifolia (Mast tree) seed powder as a reinforcement in vinyl ester resin for the development of partially biodegradable composite material. The mechanical behaviors, including tensile, impact, flexural as well as hardness of Polyalthia longifolia seed filler/vinyl ester (PLSF-VE) composite samples with various filler contents or loadings, ranging from 5 to $50 \mathrm{wt} \%$ ) were analyzed. Stability of the various samples in four different aquatic environments was studied, using water absorption test. Finally, the fractured surface structures of PLSF-VE composites were observed, using a scanning electron microscopy (SEM) and other techniques in order to comprehend and establish the correlation between the surface structure and filler-matrix interfacial adhesion or strength of the composites. The contributions of this present study include, but are not limited 
to, deeper understanding of various mechanical, thermal as well as water absorption behaviors of innovative PLSF-VE composites.

\section{Experimentation and methodology}

\section{$108 \quad 2.1 \quad$ Materials}

110 family. It is found in India, Sri Lanka and many tropical countries around the world, as an

111 ornamental street tree. In Indian subcontinent and adjacent areas, Mast tree is important in the

112 cultural traditions. Because of the close resemblance of the Ashoka tree (Saraca indica), it is

113 sometimes incorrectly identified as Ashoka tree. A $5 \mathrm{~kg}$ of Polyalthia longifolia seeds (PLS)

114 were collected from Madurai, Tamil Nadu, India. The seed coats were removed from the seed manually, and it was purified with distilled water. After purification, seeds were dried in sunlight for 2 weeks. The dried PLS were crushed to a fine powder in a ball mill, before sieving the Polyalthia longifolia seed filler (PLSF) to obtain a mean size of $25-50 \mu \mathrm{m}$. The mean

118 particle size of the milled PLSF was measured, using Horiba SZ-100 particle analyzer. The matrix used was an untreated vinyl ester resin, in addition to other chemicals: Bisphenol-Aepoxy vinyl ester resin (styrene-45\%) and N-Dimethylaniline (accelerator). Both methyl ethyl ketone peroxide and cobalt naphthenate were used as a catalyst and promoter, respectively. These chemicals were supplied by the Covai Seenu Company, India (Stalin, Nagaprasad,

123 Vignesh, \& Ravichandran, 2019).

\subsection{Manufacture of composites}

A traditional compression molding method was adopted to prepare different PLSF-VE composite samples, with filler loadings of $5-50 \mathrm{wt} \%$. Fig. 1 shows the various stages of

128 preparation of PLSF. An untreated vinyl ester resin was poured into a container and initially

129 stirred for 15 minutes to remove air bubbles, then a measured quantity of PLSF was added. To 
131 necessary to have a uniform mixture. The resin was mixed with accelerator, promoter and

132 catalyst of $1.5 \mathrm{wt} \%$, each according to the recommendation from the supplier. Later, it was

133 slowly decanted into a wax-coated mold cavity size of $200 \times 200 \times 3 \mathrm{~mm}$. After it has been

134 fully discharged into the mold cavity, the upper die was closed and the compression took place under a pressure of $100 \mathrm{kPa}$. Better curing took place after 24 hours at a room temperature, as expected (Erkliğ et al., 2016; Vigneshwaran et al., 2019).
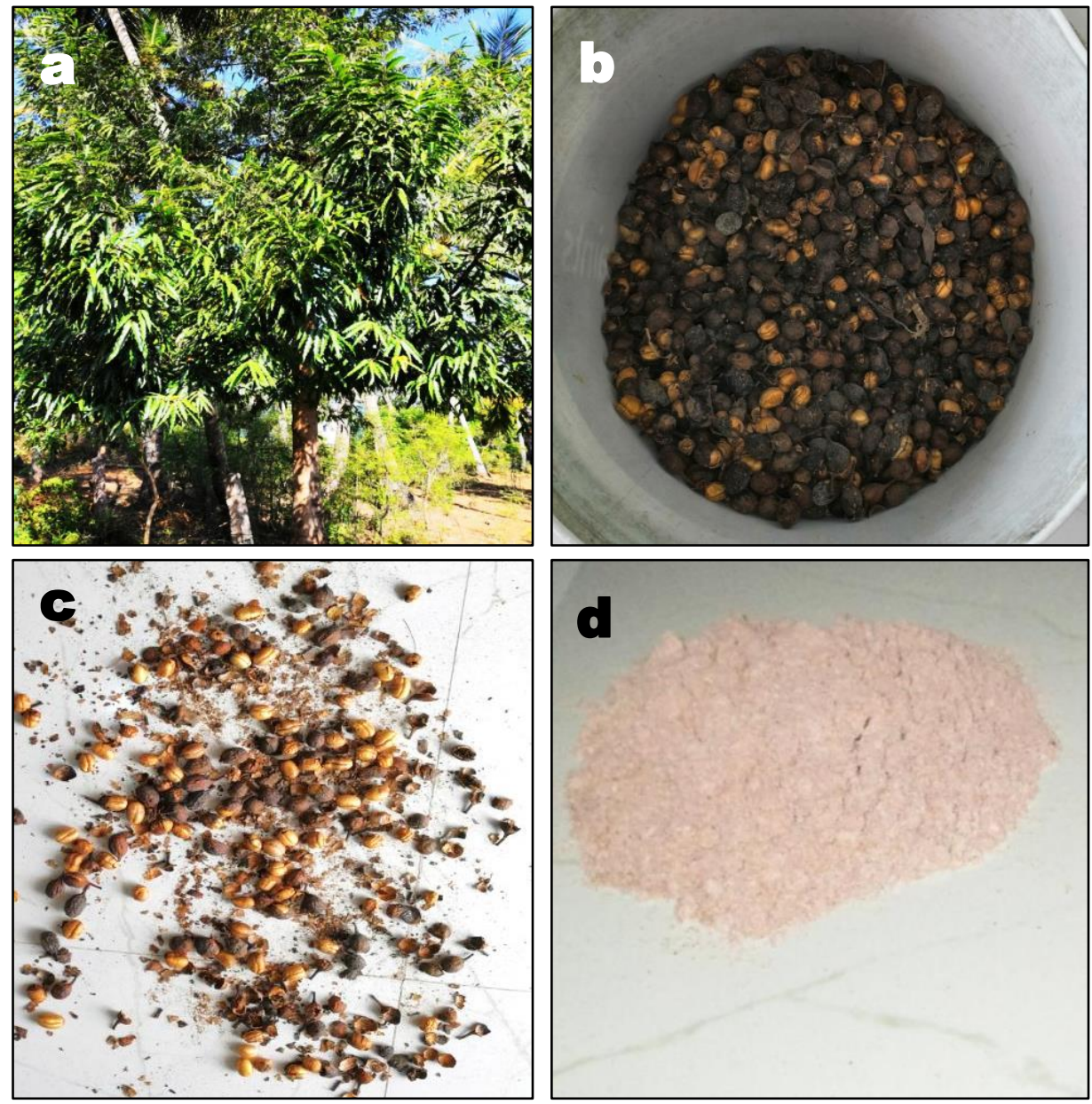

Fig. 1. Preparation of Polyalthia longifolia seed powder: Polyalthia longifolia (a) tree, (b) 


\subsubsection{Physico-chemical properties}

Chemical composition analysis was used to determine the percentage of cellulose,

158 lignin, wax, moisture, and ash content present in Polyalthia longifolia seed powder. The

159 chemical composition of the Polyalthia longifolia seed powder was determined, using the

160 following test methods: Cellulose: Kurschner and Hoffer's method (Mayandi et al., 2015),

161 lignin: Klason method (Mayandi et al., 2015), wax: Conrad method (Conrad, 1944), ash:

162 According to the ASTM E1755-61 standard (Mayandi et al., 2015), and density: Mettler Toledo

163 xsz05 balance method (Sathishkumar, Navaneethakrishnan, \& Shankar, 2012). The samples

164 were dried in an oven at $104{ }^{\circ} \mathrm{C}$ for 4 hours (Mayandi et al., 2015) to determine the moisture

165 content. For all the analyses carried out, three samples were taken and the average of three samples with standard deviation values were reported.

167

168

169

170

171

172

173

174

175

176

177

\subsubsection{X-ray diffraction}

An X'Pert-Pro diffractometer system was used to perform the X-ray diffraction (XRD) analysis of the PLSF. To obtain information about the dimensions of unit cells as well as crystalline material phase identification, a rapid analytical technique was employed. A continuous scan mode of the powder specimens was carried to obtain $2 \theta$ data, from $10^{\circ}$ to $80^{\circ}$, using a monochromatic $\mathrm{Cu}-\mathrm{K} \alpha$ radiation wavelength of $0.154 \mathrm{~nm}$. From Eq. (1), the PLSF crystallinity index $(C I)$ was evaluated.

$$
C I=\frac{I C-I a m}{I C} \times 100
$$

Where $I C$ represents maximum intensity of the peak $(2,0,0)$. This quantity corresponds to the crystalline fraction and $I_{a m}$ denotes minimum intensity of the peak $(1,1,0)$. It quantifies the amorphous fraction. Also, From Eq. (2); Scherer's formula was used to determine the crystallite size (CS) of the intermolecular forces (IMFs) for the crystallographic plane $(2,0,0)$. 
$183 C S=\frac{K \lambda}{\beta \cos \theta}$

185 Where $k=$ Scherer constant (usually 0.84 ), $\lambda=$ X-ray wavelength of $0.154 \mathrm{~nm}, b=$ peak's full width occurred at half-maximum, and $\mathrm{h}=$ Bragg angle (Vignesh, Balaji, Karthikeyan, 2016;

187 Nagarajan et al., 2020).

\subsubsection{Fourier transform infrared spectroscopy}

By using Fourier transform infrared spectroscopy (FTIR), PLSF molecular structure was analyzed, using a Perkin Elmer Spectrum RXI FTIR spectrometer in a $\mathrm{KBr}$ matrix. The recording of the spectra took place at wave number ranged from 400 to $4000 \mathrm{~cm}^{-1}$, scan rate and resolution of $32 \mathrm{scans} /$ minute and $2 \mathrm{~cm}^{-1}$, respectively. $\mathrm{KBr}$ was mixed with the Polyalthia longifolia seed powder. Then, the pellet forms were prepared through the pressurization method to obtain the FTIR spectra of the specimen in a standard condition (Kumar et al., 2018;

196 Vignesh et al., 2016).

197

\section{$2.4 \quad$ Mechanical tests}

The tensile strengths of the various samples were evaluated, using Tinius OlsenH50K. The test crosshead speed of the tensile testing machine was $1 \mathrm{~mm} / \mathrm{min}$. Five specimen replicates, with the dimension of $165 \times 10 \times 3 \mathrm{~mm}$ each, were taken for each weight percentage in accordance with ASTM D638 standard (Stalin et al., 2019). The mechanical tests on flexural strengths of all the various samples (neat vinyl ester and its PLSF-VE composites) were performed at a room temperature, according to ASTM D790-10 standard (127 x 12.7 x $3 \mathrm{~mm})$, using a digital universal testing machine (Vignesh, Balaji, \& Karthikeyan, 2017). In addition, for this same study, the impact strengths of the same various specimens were studied in agreement with ASTM D 256 standard $(65 \times 13 \times 3 \mathrm{~mm})$ at a room temperature, using a Charpy pendulum impact tester. Following the ASTM 2583 standard (Stalin et al., 2019), Barcol 
209 hardness tester (Model: VBH2) was used to determine the hardness properties of the same

210 various samples (Karthikeyan et al., 2016). In all the cases of mechanical properties, a single

211 sample T-test was performed with the confidence interval of $95 \%$ to analyze the variation

212 between the sample.

213

$2142.5 \quad$ Microstructural examination

215 A JOEL SEM was employed to analyze the ruptured surfaces of the samples after

216 tensile, flexural as well as impact tests, using scanning acceleration voltage ranged from 10 to

$21730 \mathrm{kV}$. A thin golden layer coating was done on surfaces of the fractured samples in a vacuum

218 chamber with aid of a sputter coater before the non-destructive examination was performed.

219 This was necessary to aid conductivity and produce clear micrographs.

220

221

222

\subsection{Thermal studies}

\subsubsection{Heat deflection temperature test}

A HDT-TSP model tester was used to conduct the heat deflection temperature (HDT) test in accordance with ASTM D648 standard $(60 \times 12 \mathrm{~mm} \times 3 \mathrm{~mm})$ for $0-50 \mathrm{wt} \%$ PLS filler loading composites. The loading pressure and uniform heating rate were $455 \mathrm{kPa}$ and $2 \pm 0.2$ ${ }^{\circ} \mathrm{C} / \mathrm{min}$, respectively. The HDT was noted when the test bar deflected; a standard deflection under flexural load.

\subsubsection{Thermo-gravimetric and differential thermal analyses}

The rate of change in the amount and weight of the samples were evaluated, using ModelSTA449 F3, Netzsch, Germany, during both thermo-gravimetric analysis (TGA) and differential thermal analysis (DTA). These quantities were obtained in a controlled environment and depended on either temperature or time. For all the composites, 10 milligrams

234 of powder samples of PLSF-VE composites were put in a precision-balanced alumina crucible. 
235 When determining the thermal stability of the composite samples, the temperature gradually increased to $1000{ }^{\circ} \mathrm{C}$ from a room temperature, with a heating rate within a nitrogen atmosphere and flow rate of $10{ }^{\circ} \mathrm{C} / \mathrm{min}$ and $20 \mathrm{~mL} / \mathrm{min}$, respectively (Stalin et al., 2019; Pillai, Manimaran, \& Vignesh, 2020).

\subsection{Water absorption behavior}

A minimum of three rectangular samples from each filler loading were produced from the fabricated sample plates with a dimension of $39 \mathrm{~mm} \times 10 \mathrm{~mm} \times 3 \mathrm{~mm}$, in agreement with ASTM D570-99 standard. An oven was used to dry the specimens for 24 hours (a day) at a temperature tolerance of $102 \pm 3{ }^{\circ} \mathrm{C}$. Afterwards, specimens were exposed to the selected four different aqueous environments, which were normal, salt, hot and cold water, separately. The weight of the specimens before soaked in water was measured using an electronic balance, with an accuracy up to $10^{-4} \mathrm{~g}$. Then, the specimens were soaked in normal, salt, hot and cold water at a room temperature for 24 hours, separately. A blotting paper was used to wipe off or clean water droplets on the surfaces of all the samples after they have been removed from the water, prior to each measurement.

Using Eq. (3), the absorbed moisture content of each of the samples was estimated.

252

$M(t)=100 \frac{(W t-W o)}{W o}$

Where $W_{t}$ represents the specimen weight at a specified immersion time and $W_{o}$ denotes the oven-dried weight (Akil, Cheng, Ishak, Bakar, \& Rahman, 2009; Najafi, Kiaefar, Hamidina, \& Tajvidi, 2007).

\section{Results and discussion}

\subsection{Elemental studies}

A JEOL-JSM-5610LV model was employed to examine the chemical constituents of the PLSF, during X-ray analysis. Fig. 2(a) depicts the results obtained. It was observed from 


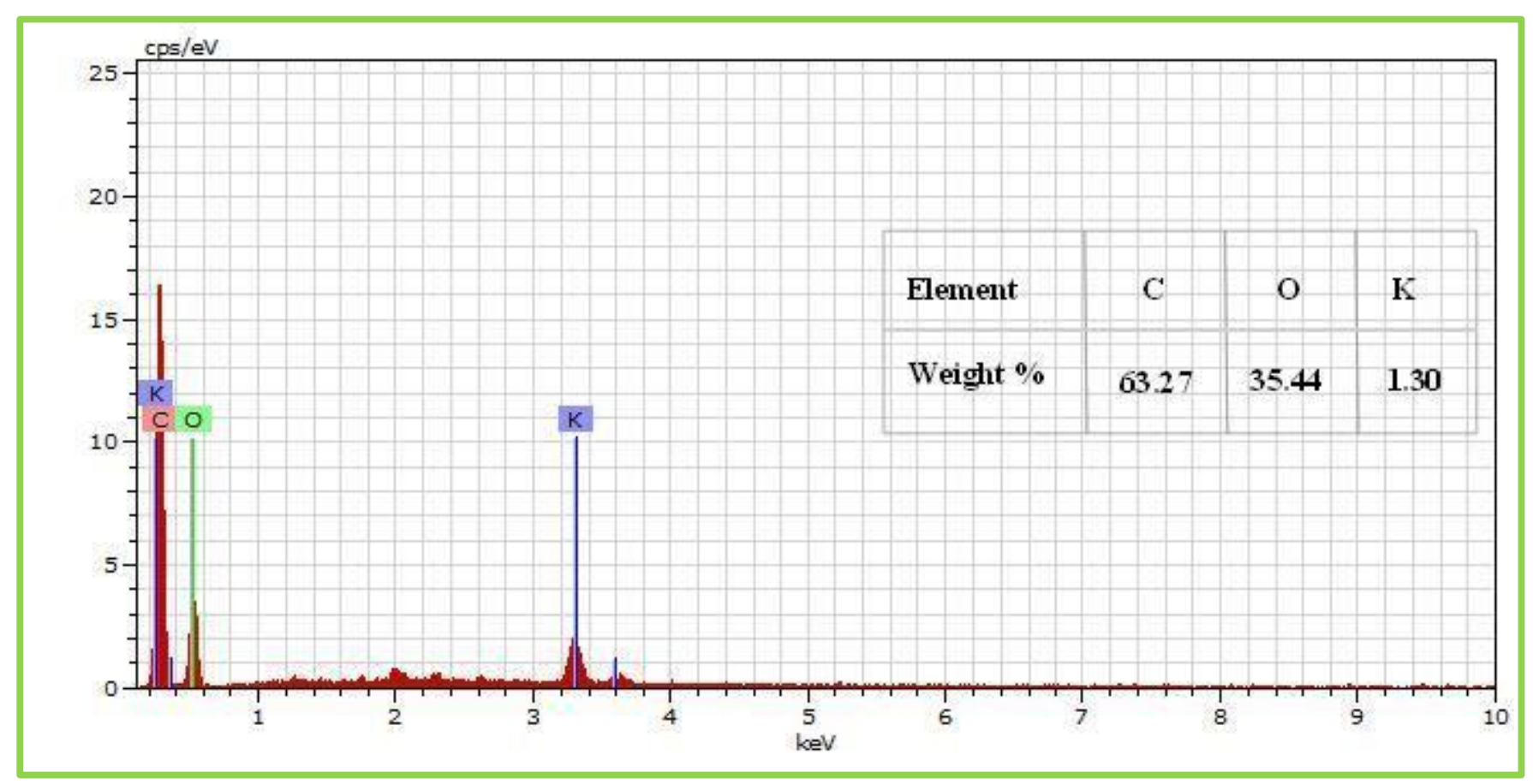

261

262

Fig. 2(a). SEM EDAX image of Polyalthia longifolia seed filler.

263 the results that the major components of PLSF included $63.27 \%, 35.44 \%$ and $1.3 \%$ of carbon,

264 oxygen and potassium, respectively.

\subsubsection{Physico-chemical properties}

The material has a low density of $0.49 \mathrm{~g} / \mathrm{cm}^{3}$. From the chemical analysis, the cellulose

content present in PLSF was $61.75 \%$, which was higher than that of palm kernel shell, coconut

sheath, rice husk, oil palm shell, groundnut shell, coconut shell and palm tree leaflet of 26.65,

$27.00,31.30,32.60,35.70,36.30$ and 40.21 , respectively. In general, the mechanical strength of the composite mainly depended on the cellulose content present in the filler/fiber. The lignin content of $19.72 \%$ present in the PLSF produced protection against a biological attack. This content was greater than that of pulp fiber, rice husk and red coconut empty fruit bunch of $12.00,14.30$ and $15.82 \%$, respectively (Nagarajan \& Balaji, 2016). The wax, ash and moisture contents present in the PLSF were $0.52,3.68$ and $8.32 \%$, respectively. 


\subsubsection{X-ray diffraction}

X-ray diffraction analysis of the PLSF was conducted, as shown in Fig. 2(b). It presents

two major crystalline peaks. The first peak estimated at $15.92^{\circ}$ was attributed to low-intensity

280 peak (110), which indicated an amorphous fraction $\left(I_{a m}\right)$. This was attributed to the fact that the

281 filler contained an amorphous material; not a crystal. The second peak estimated at $22.51^{\circ}$ was

282 traced to high-intensity peak (200), which indicated the crystalline fraction $\left(I_{C}\right)$. Therefore, the

$283 C I$ of PLSF was obtained at $65.57 \%$. The $C I$ of PLSF was greater than that of Carexmeyeriana,

coconut empty fruit bunch, Prosopis julifora, Kusha grass, Sanseveria cylindrica, sisal and jute

fibers (Balaji, Karthikeyan, \& Vignesh, 2016; Vignesh et al., 2016). The PLSF crystallite size

(L) was determined, using Scherer's formula; Eq. (2). The value peak's full-width at half-

maximum $(\beta)$ for PLSF was determined at $0.0293 \mathrm{rad}$. Furthermore, the angle of diffraction of

X-rays within a crystalline material, known as the Bragg angle $(\theta)$ was determined to be 0.196 .

289 The calculated value of $L$ for PLSF was $4.44 \mathrm{~nm}$, using Scherer's equation, which indicated the moisture absorption and chemical reactivity resistance capacities of the PLSF. The $4.44 \mathrm{~nm}$

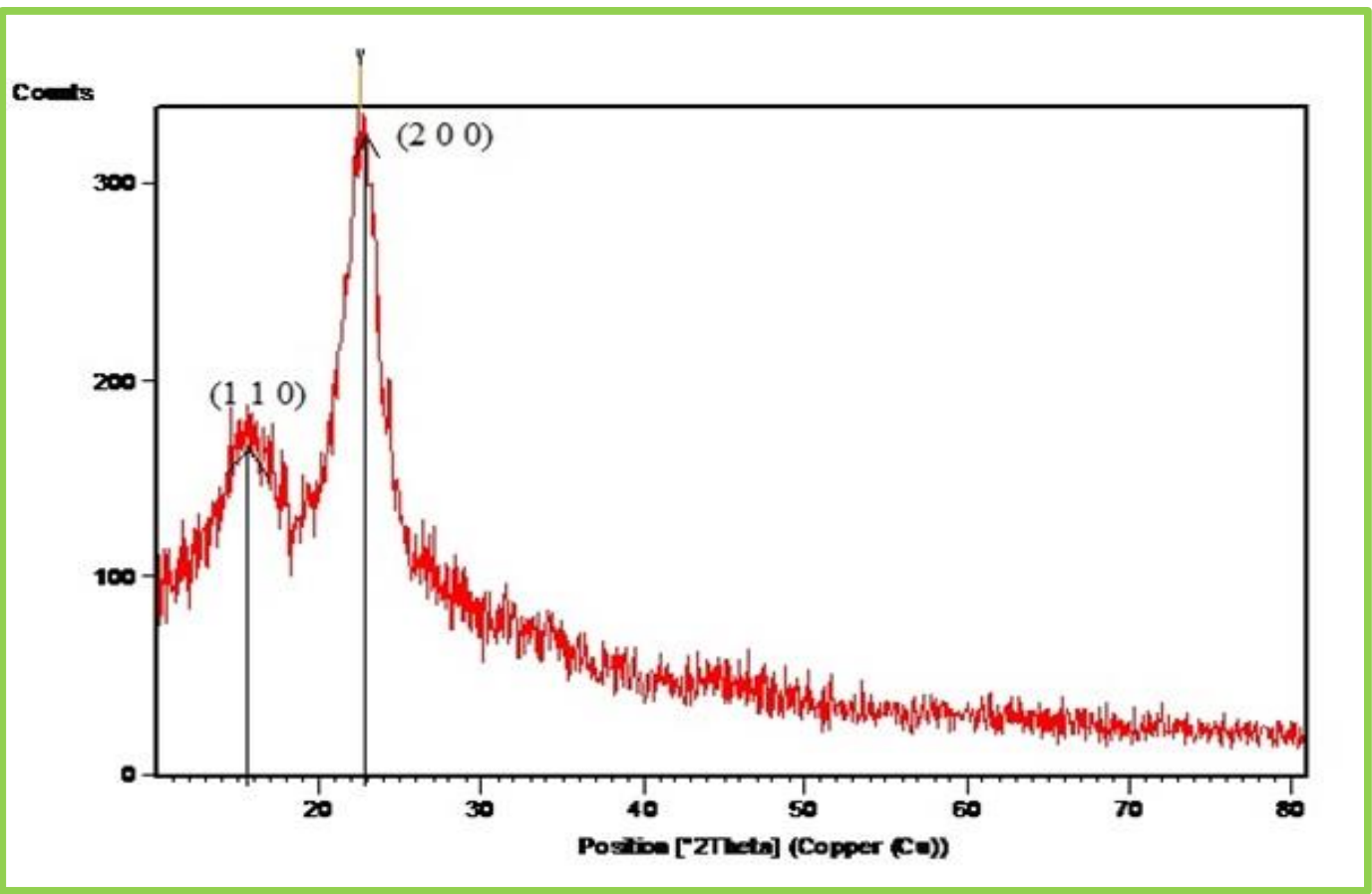


Fig. 2(b). XRD image of Polyalthia longifolia seed filler.

\subsubsection{Fourier transform infrared spectroscopy}

The results obtained from the FTIR spectroscopy of the PLSF are presented in Fig. 2(c), including the classical peaks. The spectra influenced the sharp peaks at 3850, 3417.84, 2924, $1731,1644,1382,1251,1046$ and $584 \mathrm{~cm}^{-1}$ with reduced wave numbers. There were absorption bands of various cellulosic, lignin, hemicellulosic and wax chemical functional groups, exhibited by these compounds. The peaks at around $3417-3850 \mathrm{~cm}^{-1}$ can be traced to the presence of the hydrogen bond and alcohol group $(\mathrm{O}-\mathrm{H})$ as well as the stretching vibration of the cellulose molecules of -OH groups. Additionally, the peaks at $2356 \mathrm{~cm}^{-1}$ referred to $\mathrm{CH}_{2}$ symmetrical stretching, due to the presence of wax (Sathishkumar, Navaneethakrishnan, \& Shankar, 2012).

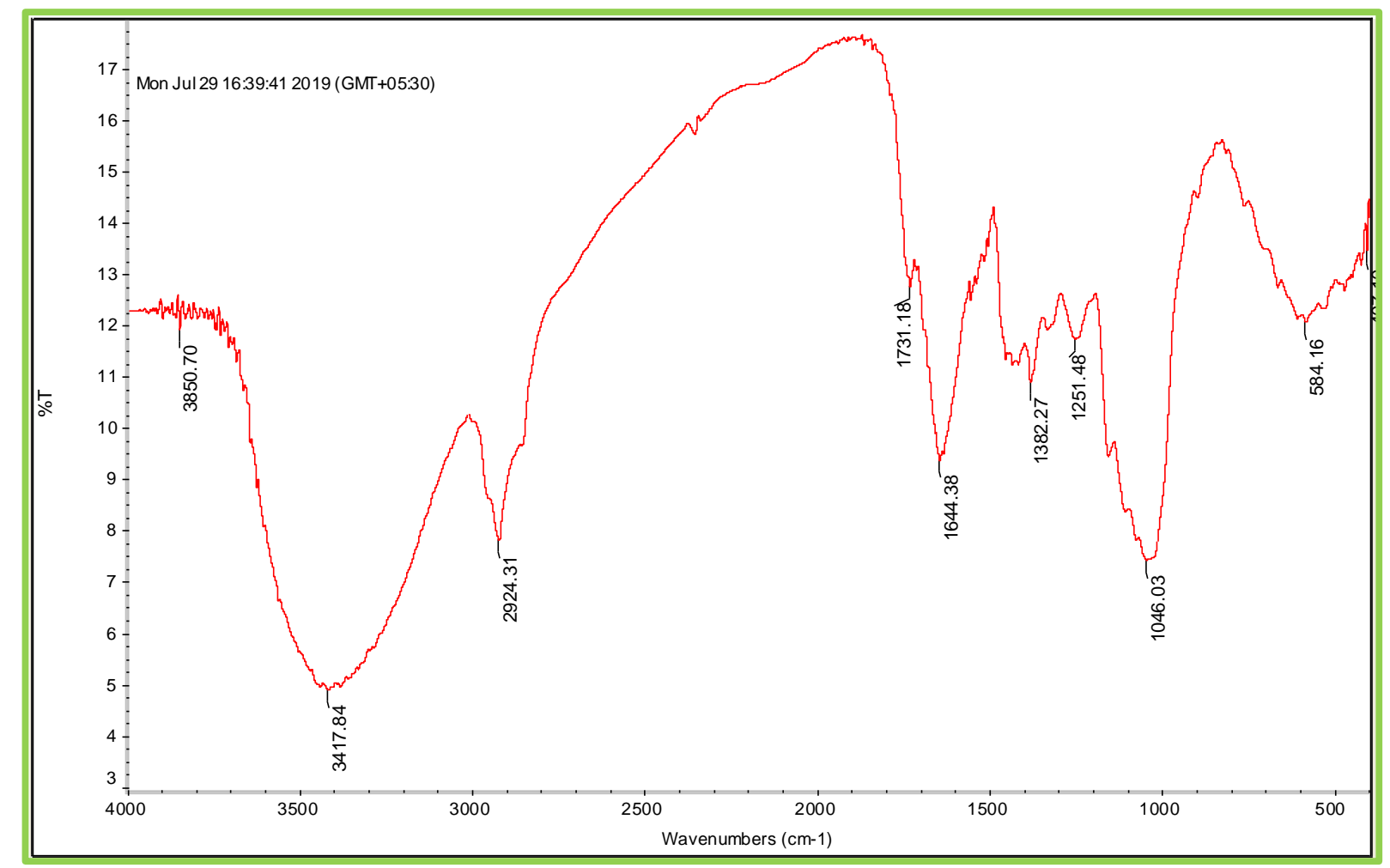

Fig. 2(c). FTIR image of Polyalthia longifolia seed filler.

The stretching vibration of carboxylic acid $(\mathrm{RCOOH})$ and carbonyl $(\mathrm{C}=0)$ groups were obtained at $1731 \mathrm{~cm}^{-1}$. The carbonyl group is present in ester (RCOOR'), while carboxylic acid 
can be found in both lignin and hemicelluloses. There was a presence of absorbed water at the peak of $1644 \mathrm{~cm}^{-1}$. Hence, this further confirmed the hydrophilicity of the PLSF. The peak value of $1251.48 \mathrm{~cm}^{-1}$ confirmed the $\mathrm{C}-\mathrm{O}$ stretch of the $-\mathrm{COCH}_{3}$ (acetyl) group, present in

334 lignin materials. Due to the out-of-plane bending of $\mathrm{OH}$, a broad band at $584.16 \mathrm{~cm}^{-1}$ was obtained (Gopinath, Ganesan, Saravanakumar, \& Poopathi, 2016).

336

337

338

339

\subsection{Mechanical behaviors}

\subsubsection{Tensile strength}

A universal testing machine (UTM) was employed to obtain the tensile properties of the various samples. The tensile test was conducted until the tensile specimens were broken. Fig. 3(a) depicts the tensile strengths and moduli obtained from the various samples. The tensile strengths obtained from the PLSF-VE samples increased from 10 to $32 \mathrm{MPa}$ with an increase in the filler contents; from 5 to $50 \mathrm{wt} \%$. The strength increased from 24 to $26 \mathrm{MPa}$, when the filler content was increased from 0 to $5 \mathrm{wt} \%$. The percentage of improvement after addition of filler was 7.69\%. For $10 \mathrm{wt} \%$ filler content, the strength of PLSF-VE composite was slightly decreased, when compared with $5 \mathrm{wt} \%$. This can be attributed to unevenly distribution between the filler and matrix. Moreover, the tensile strength of the PLSF-VE composites increased from 20 to $30 \mathrm{MPa}$, when the filler content increased from 10 to $20 \mathrm{wt} \%$. The percentage of improvement between these fillers was $33 \%$. Significantly, the ultimate tensile strength and modulus of PLSF-VE composites exhibited $32 \mathrm{MPa}$ and $1.23 \mathrm{GPa}$ at a higher PLSF weight content of $25 \mathrm{wt} \%$, because of the higher load transfer from the filler to the vinyl ester matrix. However, the tensile strength of PLSF-VE composites decreased up to $10 \mathrm{MPa}$, when the filler weight percentage was increased from 25 to $50 \mathrm{wt} \%$. From the PLSFVE composite with very low filler content, the percentage of elongation at break was very low, which indicated the brittle nature of the composites. 
358

359

360

361

362

363

364

365

366

367

368

369

370

371

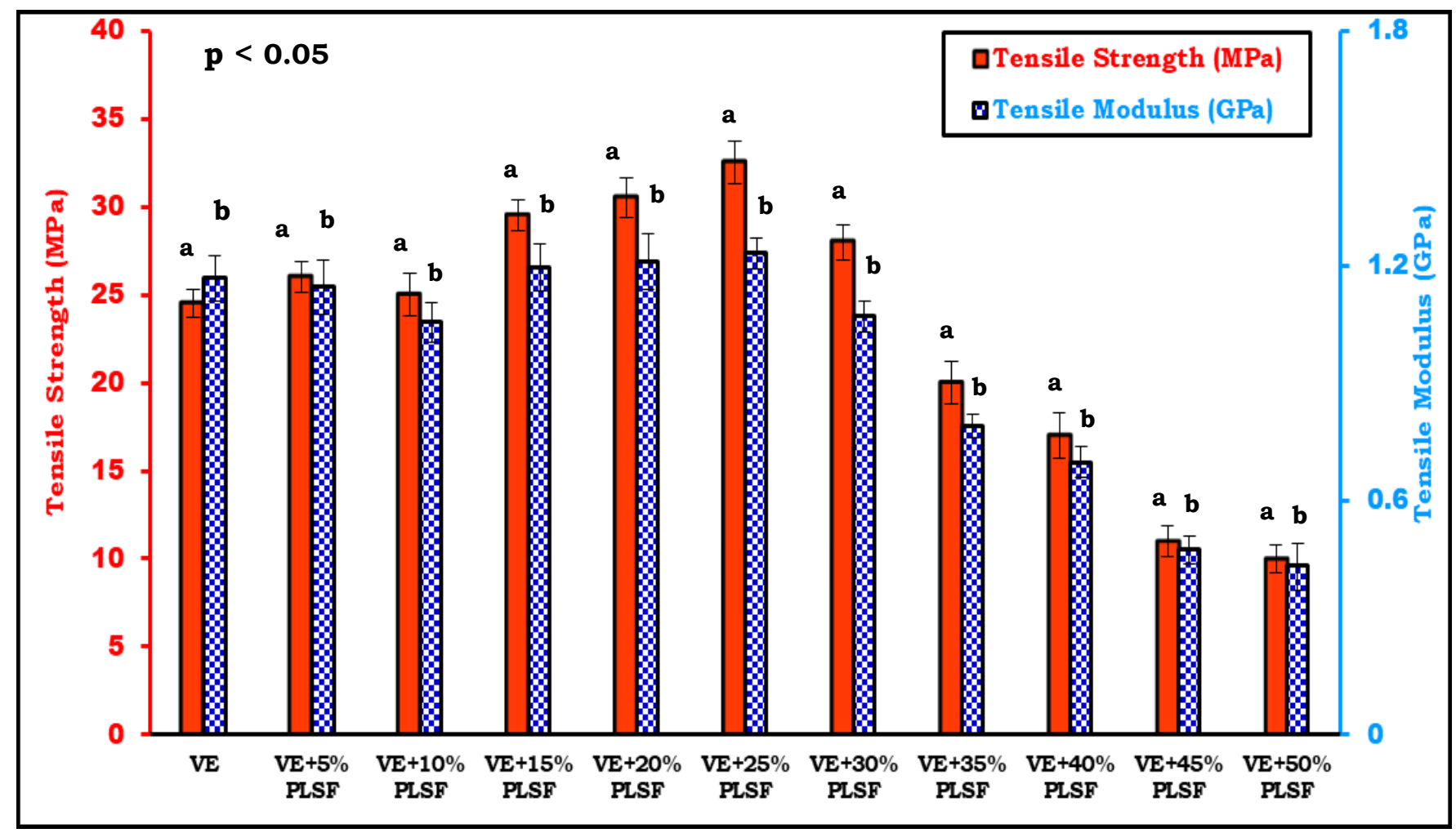

Fig. 3(a). Effects of filler loadings on tensile strengths and moduli of the various samples.

Different superscript letters indicate significant differences $(p<0.05)$.

The PLSF-VE composites exhibited an increase in the percentage of elongation at break from 2.1 to $2.64 \%$ by varying filler weight from 5 to $50 \%$. It was evident that the addition of PLSF to the vinyl ester matrix reduced its brittle nature; slightly changed the brittle property towards uncommon ductile nature of the PLSF-VE composite samples. Furthermore, the PLSF-VE composites recorded a greater tensile strength, when compared with some similar natural fiber or filler reinforced polymer (FRP) composite samples (Table 1). For instance, PLSF-VE composites were 1.17, 1.25, 2.09 and 2.59 times higher than that of composites of pistachio nutshell filler/poly (lactic acid), wood filler/epoxy, almond nutshell filler/poly (lactic acid) and walnut nutshell filler/poly (lactic acid) (Sutivisedsak et al., 2012; Kumar et al., 2018; Sutivisedsak et al., 2012; Zheng et al., 2019), respectively. 
Table 1. Comparison of mechanical properties of the Polyalthia longifolia seed filler/vinyl ester (PLSF-VE) composite with other fillers and

374 fibers-based composites.

\begin{tabular}{|c|c|c|c|c|c|c|}
\hline Composite materials & $\begin{array}{l}\text { Manufacturing } \\
\text { process }\end{array}$ & $\begin{array}{c}\text { Tensile } \\
\text { strength } \\
(\mathrm{MPa})\end{array}$ & $\begin{array}{c}\text { Flexural } \\
\text { strength } \\
(\mathrm{MPa})\end{array}$ & $\begin{array}{l}\text { Impact } \\
\text { strength } \\
\left(\mathrm{kJ} / \mathrm{m}^{2}\right)\end{array}$ & Hardness & Reference \\
\hline Polyalthia longifolia seed filler/vinyl ester & $\begin{array}{l}\text { Compression } \\
\text { molding }\end{array}$ & $9-32.5$ & $44-125$ & $10-31.09$ & $23-36.5$ & Present work \\
\hline Date seed filler/vinyl ester & $\begin{array}{l}\text { Compression } \\
\text { molding }\end{array}$ & $10.5-40.3$ & $46-149$ & $9.43-17.03$ & $20.33-51$ & $\begin{array}{l}\text { (Nagaprasad et } \\
\text { al., 2019) }\end{array}$ \\
\hline Palm kernel shell/unsaturated polyester resin & Hand lay-up & $2-20$ & $5-38$ & $3.5-5$ & $10-15$ & $\begin{array}{c}\text { (Adeosun et al., } \\
\text { 2016) }\end{array}$ \\
\hline $\begin{array}{l}\text { Sugarcane bagasse/unsaturated polyester } \\
\text { resin }\end{array}$ & Hand lay-up & $2-24$ & $18-50$ & $3.5-7$ & $8-14$ & $\begin{array}{l}\text { (Adeosun et al., } \\
\text { 2016) }\end{array}$ \\
\hline Pineapple chaffs/unsaturated polyester resin & Hand lay-up & $2-23$ & $9-38$ & $3.5-5.2$ & $9-13$ & $\begin{array}{c}\text { (Adeosun et al., } \\
\text { 2016) }\end{array}$ \\
\hline Pecan nutshell/poly lactic acid & Injection molding & 61 & 109 & -- & -- & $\begin{array}{l}\text { (Sánchez-Acosta } \\
\text { et al., 2019) }\end{array}$ \\
\hline Pistachio nutshell filler/poly (lactic acid) & Injection molding & $8-29.2$ & -- & -- & -- & $\begin{array}{c}\text { (Sutivisedsak et } \\
\text { al., 2012) }\end{array}$ \\
\hline Almond nutshell filler/poly (lactic acid) & Injection molding & $10-16.2$ & -- & -- & -- & $\begin{array}{l}\text { (Sutivisedsak et } \\
\text { al., 2012) }\end{array}$ \\
\hline Sewage sludge ash/polyester & Hand lay-up & $40-50.2$ & $73-107.2$ & -- & -- & $\begin{array}{l}\text { (Erkli ̌̆ et al., } \\
\text { 2016) }\end{array}$ \\
\hline Fly ash/polyester & Hand lay-up & $41-51.9$ & $82-109.9$ & -- & -- & $\begin{array}{c}\text { (Erkli ğ et al., } \\
\text { 2016) }\end{array}$ \\
\hline
\end{tabular}




\begin{tabular}{|c|c|c|c|c|c|c|}
\hline wood filler/epoxy & Hand lay-up & $6-27.8$ & -- & -- & -- & $\begin{array}{c}\text { (Kumar et al., } \\
\text { 2018) }\end{array}$ \\
\hline Thyme herbs/polyethylene & Injection molding & $19-24$ & $23-36$ & $2-3.3$ & $53-60$ & $\begin{array}{c}\text { (Montanes et al., } \\
\text { 2018) }\end{array}$ \\
\hline Tamarind seed filler/vinyl ester & $\begin{array}{l}\text { Compression } \\
\text { molding }\end{array}$ & $9-34.1$ & $47-121$ & $7-14$ & $23-42.33$ & $\begin{array}{c}\text { (Stalin et al., } \\
\text { 2019) }\end{array}$ \\
\hline Roselle/sugar palm fiber/vinyl ester & Hand lay-up & $15-24.65$ & $58-110$ & -- & -- & $\begin{array}{l}\text { (Razali, Sapuan, } \\
\text { \& Razali, 2018) }\end{array}$ \\
\hline Betel nut husk fiber/vinyl ester & $\begin{array}{l}\text { Compression } \\
\text { molding }\end{array}$ & $39-100$ & $60-80$ & $2-5.7$ & -- & (Akil et al., 2009) \\
\hline Sisal fiber/epoxy & Hand lay-up & $5-15.64$ & $22-60.89$ & $5-13.24$ & -- & $\begin{array}{c}\text { (Owen, Ogunleye } \\
\text { \& Achukwu, } \\
\text { 2015) }\end{array}$ \\
\hline Nappier grass fiber/epoxy & Hand lay-up & $21-39.53$ & $45-76.21$ & -- & -- & $\begin{array}{c}\text { (Kommula, } \\
\text { Reddy, Shukla, } \\
\text { Marwala, \& } \\
\text { Rajulu, 2014) }\end{array}$ \\
\hline Glass fiber/banana chopped filler/polyester & Hand lay-up & $41-45$ & $80-90$ & -- & -- & $\begin{array}{c}\text { (Gupta, Gupta, } \\
\text { Dhanola, \& } \\
\text { Raturi, 2016) }\end{array}$ \\
\hline Glass fiber/rice husk/polyester & Hand lay-up & $41-43$ & $80-83$ & -- & -- & $\begin{array}{c}\text { (Gupta et al., } \\
\text { 2016) }\end{array}$ \\
\hline Carbon fiber/cement by-pass dust/vinyl ester & $\begin{array}{c}\text { Gravity casting } \\
\text { method }\end{array}$ & $10-18.5$ & $28-34.5$ & -- & -- & $\begin{array}{l}\text { (Gangil, Patnaik, } \\
\text { \& Kumar, 2013) }\end{array}$ \\
\hline
\end{tabular}




\subsubsection{Flexural strength}

The flexural strengths and moduli of the various samples are depicted in Fig. 3(b). Addition of PLSF to the vinyl ester matrix used (neat resin) increased or improved the flexural strengths of the various PLSF-VE composite samples up to a filler loading of $35 \mathrm{wt} \%$. The increasing trend was more prominent between the filler contents of 15 and $25 \mathrm{wt} \%$. Similarly, the flexural modulus of the PLSF-VE composite was enhanced when vinyl ester matrix was reinforced with PLSF material. Flexural strength of $78 \mathrm{MPa}$ and modulus of $3.64 \mathrm{GPa}$ were recorded by the vinyl ester. By adding $5 \mathrm{wt} \%$ of PLSF to the matrix, the flexural strength of 100.4 MPa was increased by $28.72 \%$. Meanwhile, when the filler loading percentage was increased from 5 to 10 and $15 \mathrm{wt} \%$, the flexural strengths of the PLSF-VE composites were respectively decreased from 100.4 to 84 and $92 \mathrm{MPa}$. But, beyond $15 \mathrm{wt} \%$, the flexural strength was gradually increased up to $35 \mathrm{wt} \%$ of PLSF reinforced composites. With $20 \mathrm{wt} \%$ filler loading, a sudden increase was observed, due to the PLSF content which reduced a quite amount of brittle property of the vinyl ester matrix. Significantly, the $25 \mathrm{wt} \%$ PLSF composite achieved the maximum flexural strength behavior of $125 \mathrm{MPa}$. Hence, it was evident that 25 wt $\%$ PLSF-VE composite recorded an optimum value, which was $60.26 \%$ higher than the neat vinyl ester resin. This can be attributed to the proper reinforcement-matrix interfacial adhesion. The flexural properties (strength and modulus) of the composite started to decrease immediately after the threshold value of $25 \mathrm{wt} \%$ and reduced much more with $35 \mathrm{wt} \%$ filler loading and other higher contents. This can be traced to an occurrence of weak interfacial bonding between higher contents of PLSF and vinyl ester resin. The flexural strength of PLSFVE composite was $14.68,56.25,105.29,262.32$ and $247.22 \%$ higher than that of pecan nutshell/polylactic acid, betel nut husk fiber/vinyl ester, sisal fiber/epoxy, carbon fiber/cement by-pass dust/vinyl ester and thyme herbs/polyethylene composites (Sánchez-Acosta et al., 
$401 \quad$ Montanes et al., 2018), respectively.

402

403

404

405

406

407

408

409

410

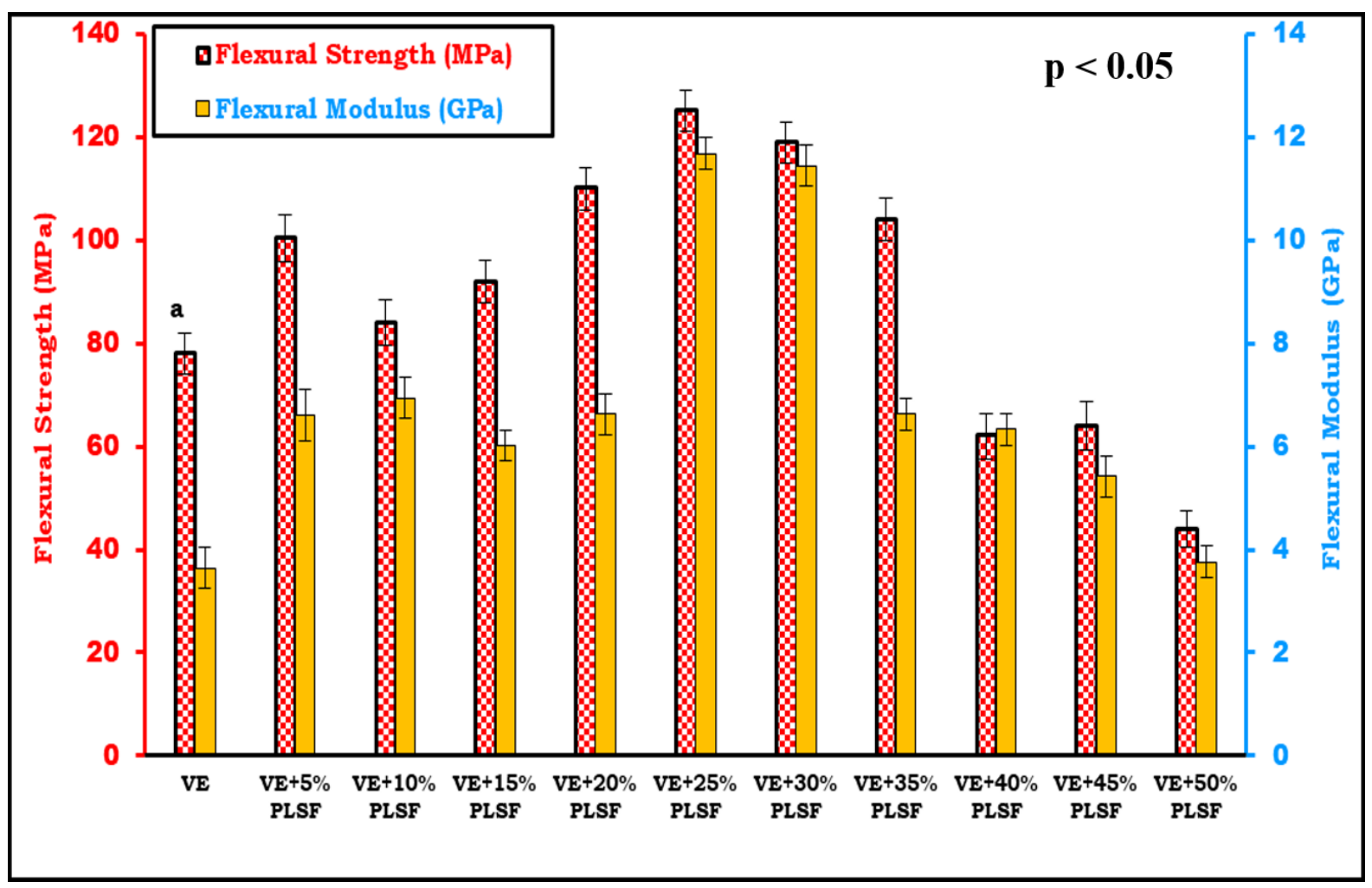

Fig. 3(b). Effects of filler loadings on flexural strengths and moduli of the various samples. Different superscript letters indicate significant differences $(\mathrm{p}<0.05)$.

\subsubsection{Impact strength}

The capability of a material to resist or withstand a suddenly applied load is referred to as impact strength. While, the ability of a workpiece to resist plastic deformation under an indenter is known as hardness. Fig. 3(c) depicts the impact strength and hardness properties of the various samples. The impact strength of pure vinyl ester resin was $11.83 \mathrm{~kJ} / \mathrm{m}^{2}$. But, it was increased to $13.50,23.91$ and $26.24 \mathrm{~kJ} / \mathrm{m}^{2}$ after respectively reinforced with filler contents of 5, 10 and $15 \mathrm{wt} \%$. It was evident from the experimental results obtained that an improvement in impact strength was recorded up to $45 \mathrm{wt} \%$ of PLSF content. However, there was a significant decrease with 50 wt\% PLSF-VE composite. It was therefore evident that the 
maximum or optimum impact strength was recorded with the $25 \mathrm{wt} \%$ PLSF-VE composite.

418 The improved interfacial property of PLSF-VE composite supported its increased impact

419 strength by $1.83,2.22,2.35,5.45$ and 9.42 times higher than that of date seed filler/vinyl ester,

420 tamarind seed filler/vinyl ester, sisal fiber/epoxy, betel nut husk fiber/vinyl ester and thyme

421 herbs/polyethylene composites (Nagaprasad et al., 2019; Stalin et al., 2019; Owen, Ogunleye, \& Achukwu, 2015; Akil et al., 2009; Montanes et al., 2018), respectively.

423

424
425

426

427

428

429

430

431

432

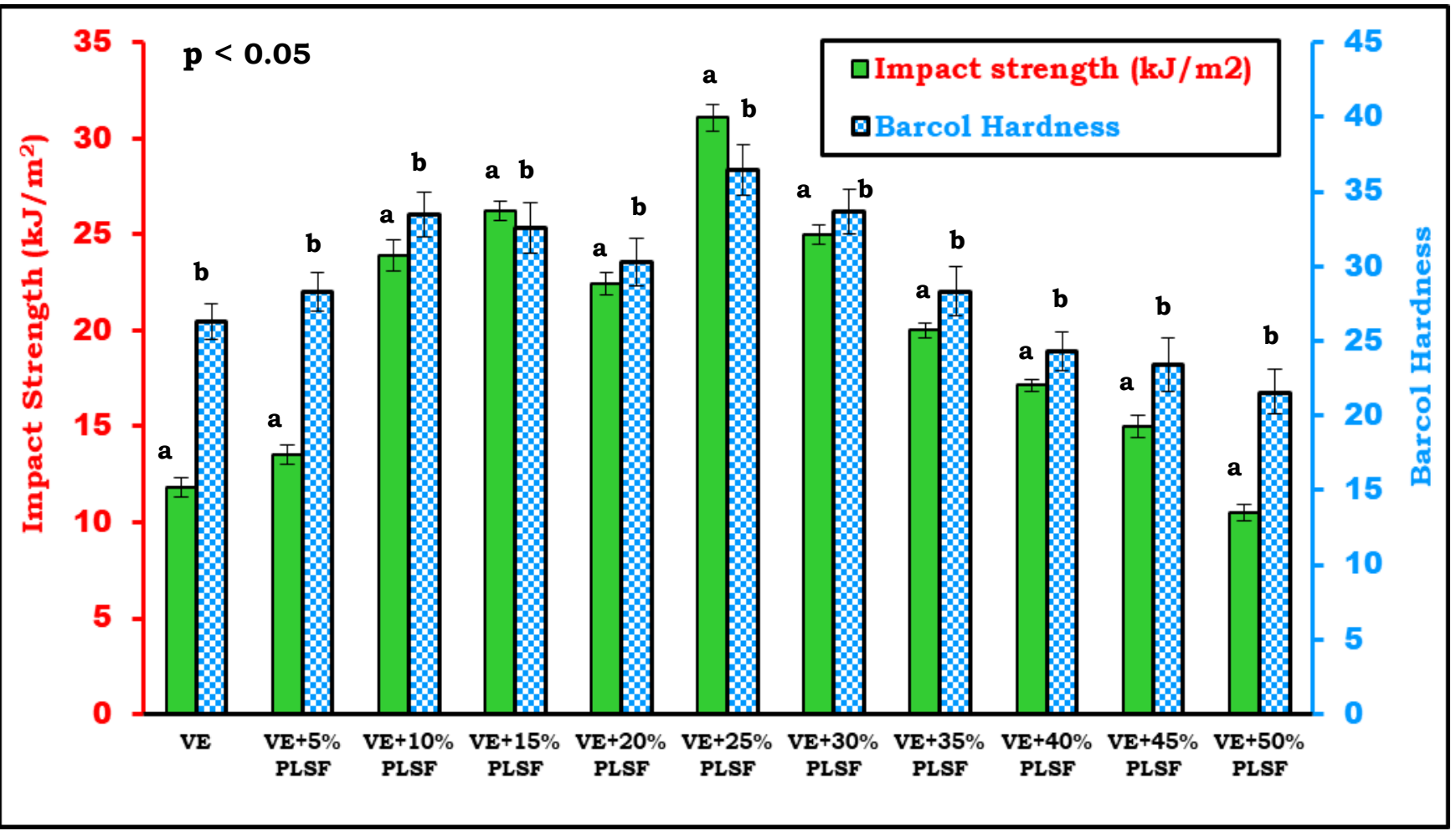

Fig. 3(c). Effects of filler loadings on impact strengths and hardness of the various samples. Different superscript letters indicate significant differences $(\mathrm{p}<0.05)$.

\subsubsection{Hardness property}

An increase in the PLS filler loadings resulted to an increase in the hardness values of the composites. The neat vinyl ester resin recorded a hardness value of 26.33. It was observed from the results obtained (Fig. 3(c)) that the hardness values increased from 26.33 to an optimum value of 36.5 with $25 \mathrm{wt} \%$ PLSF reinforced composite sample, and up to $35 \mathrm{wt} \%$ of 
435 filler content. Afterwards, the hardness value decreased up to $50 \mathrm{wt} \%$ of filler loadings. The 436 observed increase in the hardness value, as a function of filler loading, especially with $25 \mathrm{wt} \%$

437 of filler content can be ascribed to the even distribution of the filler particles and a good filler438 matrix interfacial bonding. These reduced the penetration of the indenter on the surfaces of the 439 PLSF reinforced composite test specimens.

440

\subsection{Microstructural examination}

Fig. 4 depicts the SEM micrographic surfaces of the PLSF-VE fractured specimens, 443 after tensile tests. The morphology in Fig. 4(a) shows that there were occurrences of filler pull444 out and cavity formation on the $40 \mathrm{wt} \%$ PLSF-VE composite specimen fractured surfaces. 445 Consequently, micro cracks were simply spread on the vinyl ester matrix. It later exhibited 446 poor tensile strength. The resultant poor filler-matrix interfacial strength caused an ineffective 447 stress transfer. In Fig. 4(b), a few filler accumulations were observed and filler was completely 448 wetted with the matrix. It supported the excellent adhesion between filler and matrix. There 449 was no filler pull-out that predominantly occurred. Consequently, it was observed that $25 \mathrm{wt} \%$ 450 PLSF-VE composite produced a maximum tensile strength. This excellent performance was 451 attributed to the effective filler-matrix stress transfer within the composite structure. 

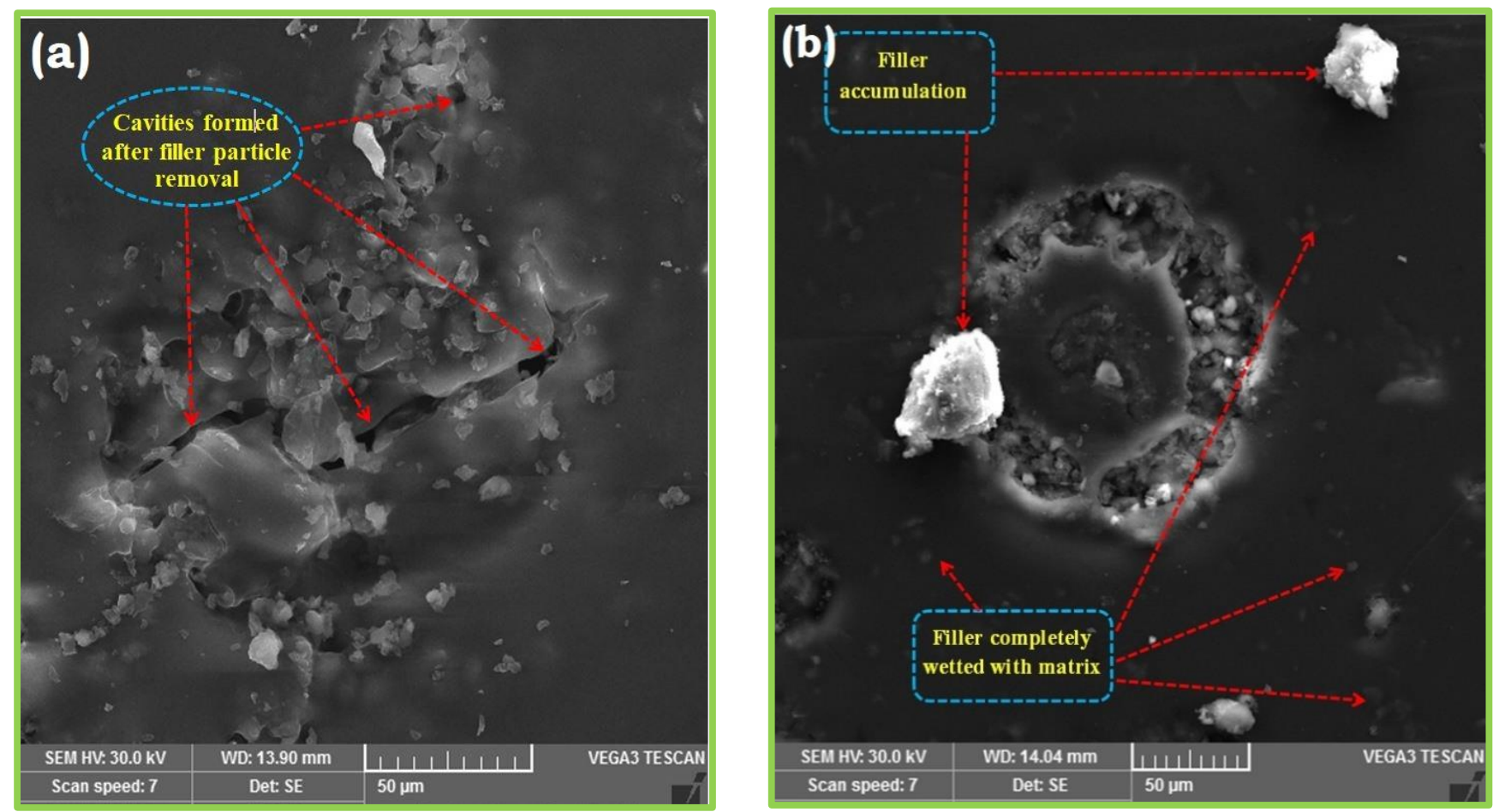

Fig. 4. SEM images of fractured tensile specimens of PLSF-VE composites with filler

Moreover, the SEM micrographic fractured PLSF-VE specimens, after subjected to the interlocking, while filler-matrix interfacial adhesion strength depended on the filler-matrix inter-diffusion level (Kommula et al., 2014; Owen et al., 2015). From Fig. 5(b), better bonding between filler and the matrix was observed, with the presence of a very few voids with $25 \mathrm{wt} \%$ of filler loadings. This resulted in a maximum flexural strength of the $25 \mathrm{wt} \%$ PLSF-VE composite sample. 

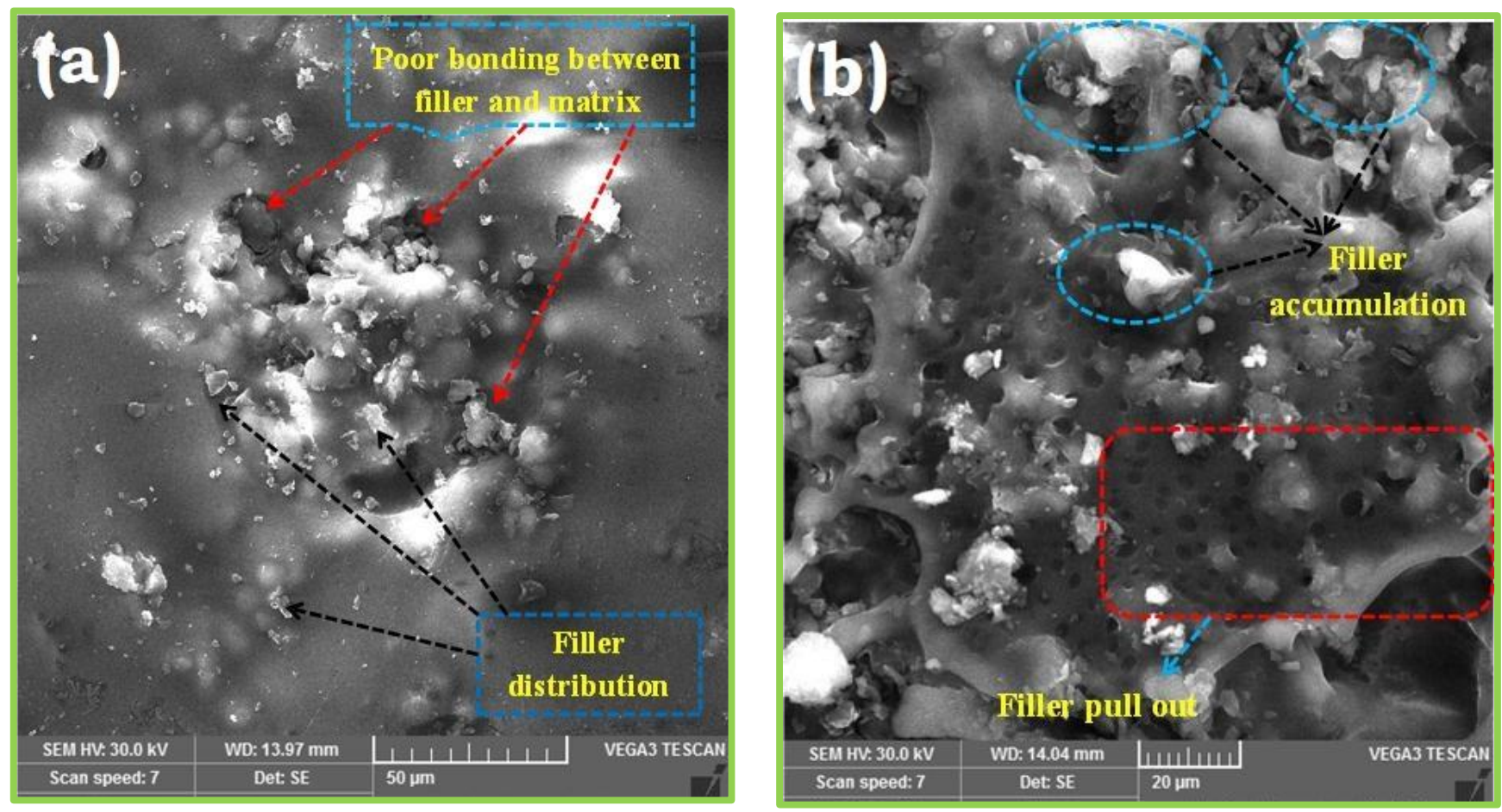

471

472

473

474

475

476

477

478

479

480

481

482

483

484

485

486

487

Fig. 5. SEM micrographs of fractured flexural specimens of PLSF-VE composites with filler contents of (a) 40 and (b) $25 \mathrm{wt} \%$.

The cross-sectional surfaces of the PLSF-VE impact fractured composites were analyzed.

The SEM micrographs of the composite samples are shown in Fig. 6. Fig. 6(a) shows the composite with $25 \mathrm{wt} \%$ of PLS filler loadings, indicating excellent interaction between the filler and vinyl ester resin. Therefore, the formation of voids within the composite sample was reduced. Also, this reflected in the excellent impact strength of the $25 \mathrm{wt} \%$ PLSF-VE composite. Fig. 6(b) depicts the $50 \mathrm{wt} \%$ PLS filler loaded composites. An increase in the filler loading resulted to a decrease in the quantity of matrix within the composite system. Therefore, de-bonding, voids, weak interfacial bonding and filler pull-out occurred. Reinforcing particle or filler usually pulls out as a replacement for fracture whenever there is either ineffective particle/fiber-matrix interaction or weak interface, or both. Hence, it decreased the structural capability, including mechanical behaviors of the composite (Sánchez-Acosta et al., 2019).

Composites with a higher percentage of filler loading reduced the plastic region of the 

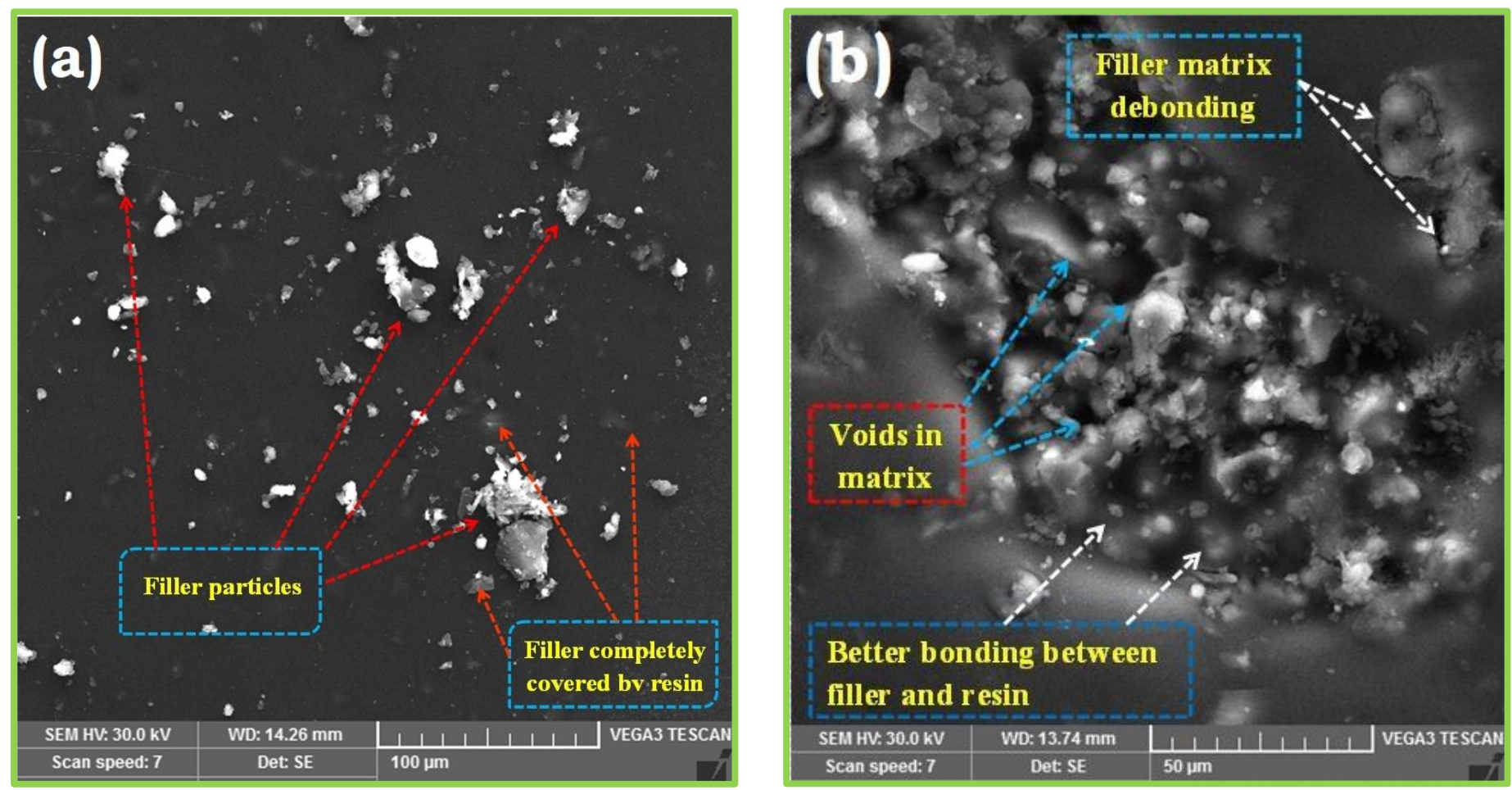

490

491 Fig. 6. SEM micrographs of fractured impact specimens of PLSF-VE composites with filler

492 contents of (a) 25 and (b) $50 \mathrm{wt} \%$.

493

\section{$494 \quad 3.4 \quad$ Thermal analysis}

\subsubsection{Heat deflection temperature}

496

A measured temperature that causes a material to deflect by $0.25 \mathrm{~mm}$ when subjected

497 to a load of $455 \mathrm{kPa}$ is technically referred to as a heat deflection temperature (HDT); simply

498 called a softening point of a material. It is an essential factor usually considered by the

499 industrial designers of polymer-based engineering components. All the samples recorded

500 different HDT values, as depicted in Fig. 7. The HDT value of neat vinyl ester resin (with 0

501 wt\% filler content) was $53{ }^{\circ} \mathrm{C}$. The HDT value of PLSF-VE samples steeply increased when

502 there was an increase in the filler weights. Precisely, with $10 \mathrm{wt} \%$ of PLSF, the HDT was $17 \%$

503 much greater than that of the pure resin. The HDT of $25 \mathrm{wt} \%$ PLSF-VE composite significantly 
increased to a maximum value of $66{ }^{\circ} \mathrm{C}$. This value was $24.53 \%$ greater when compared with the value recorded from the neat vinyl ester resin. Importantly, a continuous decrease in the HDT was observed when the filler content was increased above $25 \mathrm{wt} \%$.

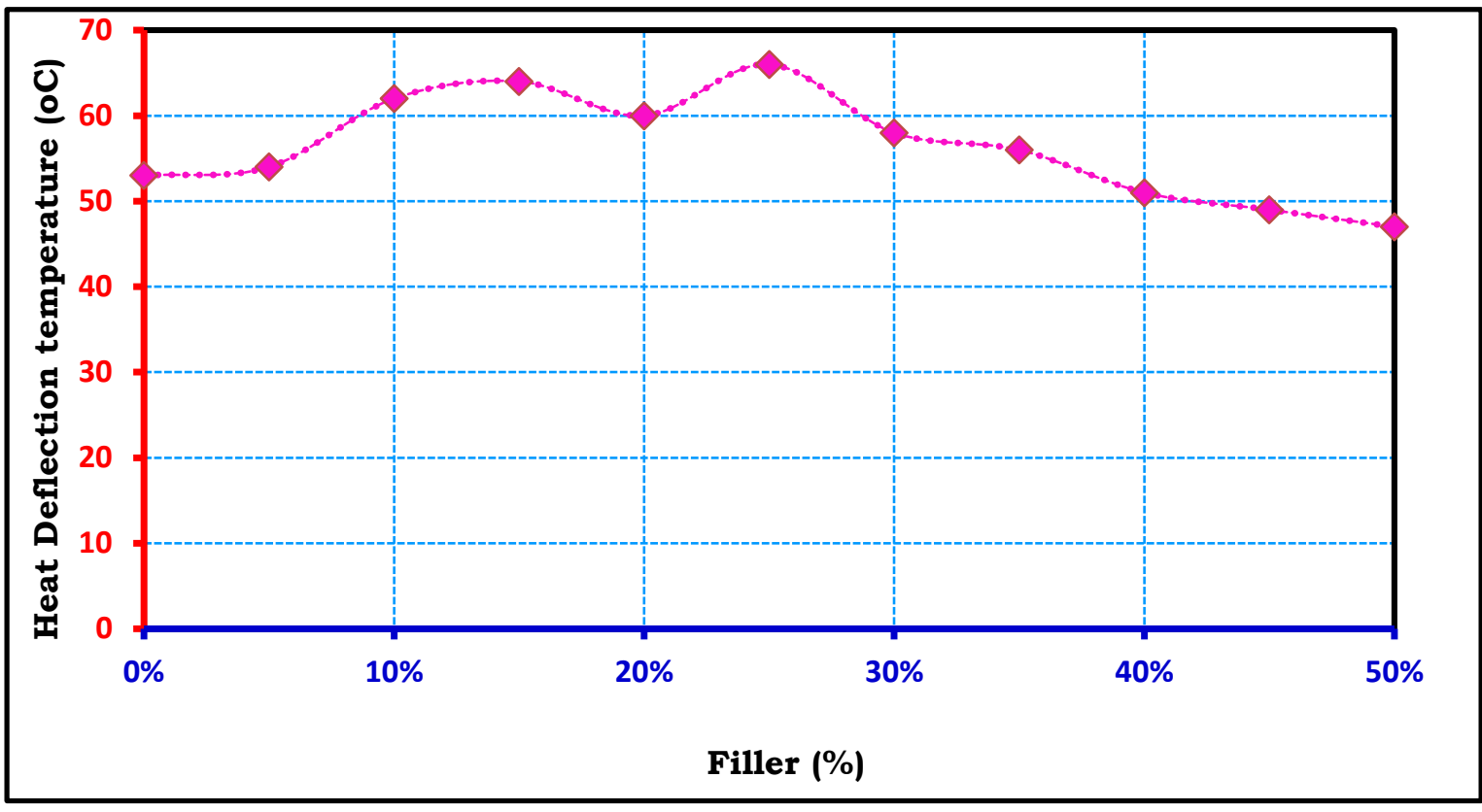

Fig. 7. Heat deflection temperature versus filler loadings of the various samples.

\subsubsection{Thermo-gravimetric and differential thermal analyses}

512 Thermal stability and degradation behaviors of both PLS filler and PLSF-VE composites

513 were determined using TGA. Figs. 8(a)-(d) show the thermal degradation profiles obtained

514 from the TGA as well as DTA curves of the PLS filler, neat vinyl ester resin, PLSF-VE samples

515 with filler contents of 25 and $50 \%$, respectively. There was an increase in temperature from 25

$516{ }^{\circ} \mathrm{C}$ to $1000{ }^{\circ} \mathrm{C}$ for the various components of the specimens to burn and the percentage of the

517 mass loss in each specimen was measured. The test results depicted three phases of thermal

518 degradation. The stage 1 of the dehydration process was observed below $150{ }^{\circ} \mathrm{C}$, stage 2 was

519 between 150 and $400{ }^{\circ} \mathrm{C}$ and followed by the last stage below $400{ }^{\circ} \mathrm{C}$. The inception stage of

520 PLS filler thermal degradation was recorded above $95^{\circ} \mathrm{C}$ and major weight loss was occurred 
between 290 and $310^{\circ} \mathrm{C}$. The pure vinyl ester resin recorded thermal stability up to $385^{\circ} \mathrm{C}$.

522 The resin exhibited a major weight loss between 300 and $385^{\circ} \mathrm{C}$. The 25 and $50 \mathrm{wt} \%$ PLSF-

523 VE composite samples recorded different major weight losses at $430{ }^{\circ} \mathrm{C}$ and $410{ }^{\circ} \mathrm{C}$,

524 respectively. Summarily, the thermal stability of PLSF-VE composite was $11.69 \%$ higher than

525 that of the neat vinyl ester resin.

526

527

528

529

530

531

532

533

534

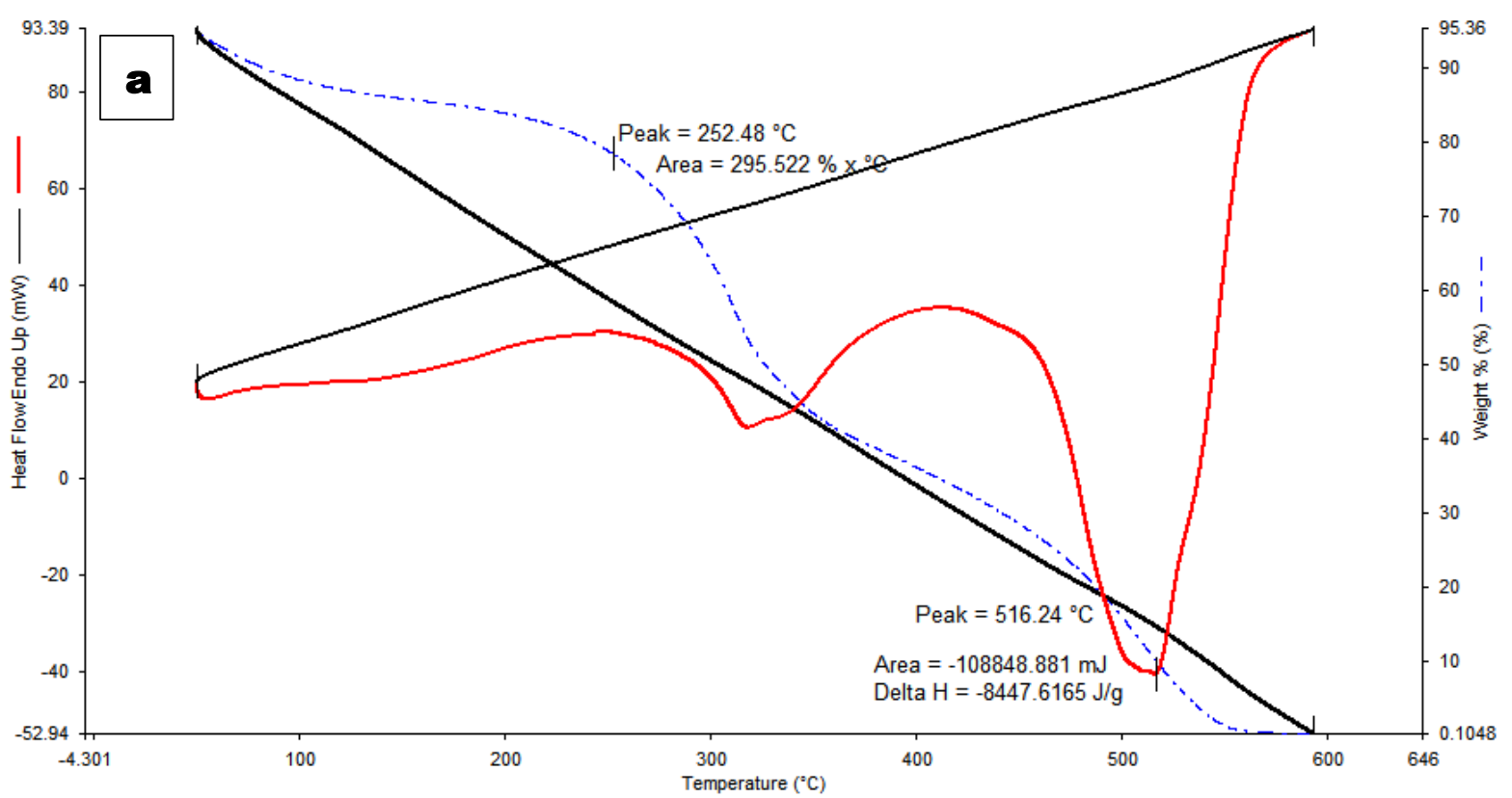

535

536

537

538

539

540

541

542

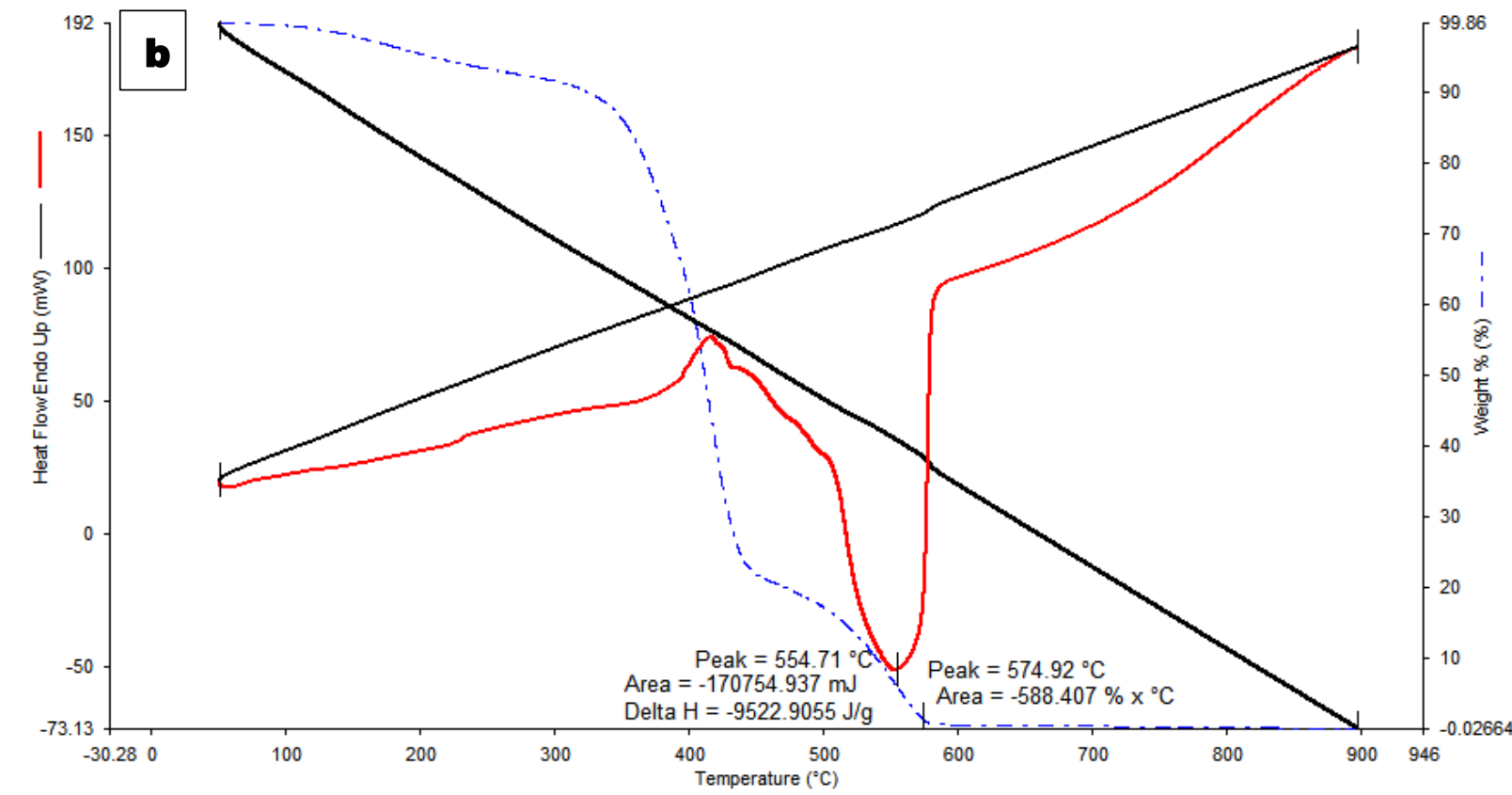




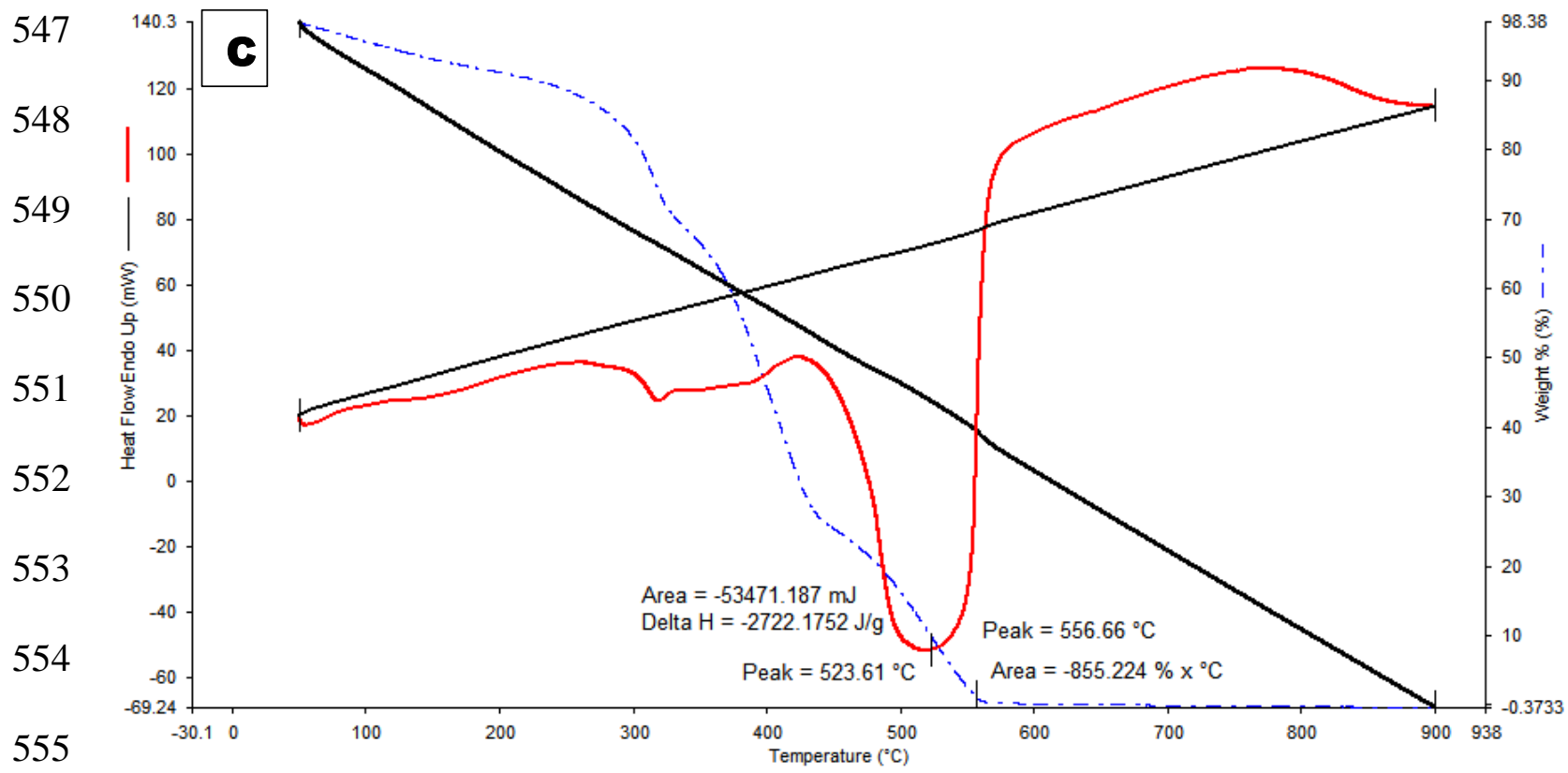

556

557

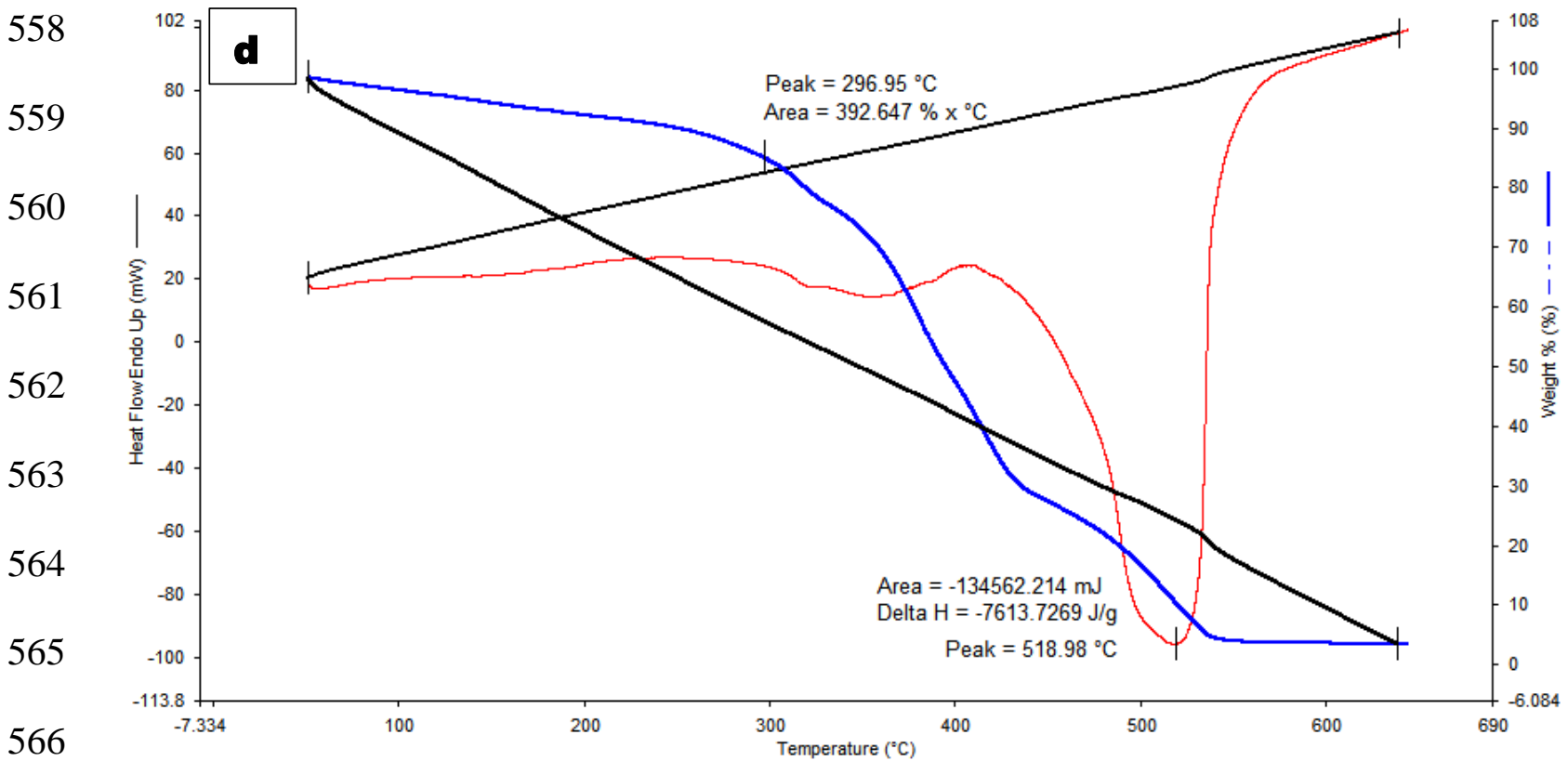

567 $\mathrm{wt} \%$ filler loadings. 


\subsection{Water absorption behavior}

The water absorption behaviors of the various samples under normal, salt, hot and cold

575 water conditions are presented in Fig. 9. An increase in the water absorption was observed

576 when there was an increase in the PLSF loadings, as shown in the moisture absorption curve.

577 This was attributed to the hydrophilicity property of the PLSF material. The hydrophobic

578 nature of the resin supported the lower quantity of water absorption exhibited by the composite

579 samples with lower filler contents (5 - $25 \mathrm{wt} \%)$; they were richer in resin when compared with

580 higher filler reinforced composites (above $25 \mathrm{wt} \%$ ). After $25 \mathrm{wt} \%$ PLSF loading, the water

581 absorption percentage was increased, as a result of the existence of more microvoids and less

582 vinyl ester resin (much hydrophilic filler) in the composite samples. It was evident from Fig. 9

583 that the absorption percentage was very small, till an optimal content of $25 \mathrm{wt} \%$. The best

584 performance can be traced to the good filler-matrix interaction, which caused a reduction in the

585 movement or speed of the diffusing particles. Expectedly, there was an increase in the

586 diffusivity process of the composite samples in the hot water. Therefore, it recorded the

587 maximum percentage of water absorption, when compared with the other three environments.

588 A similar trend of result has been reported for the same vinyl ester matrix when reinforced with

589 tamarind seed filler to produce various similar biocomposites (Stalin et al., 2019).

590 Nevertheless, in the sea or saltwater, a slow penetration occurred. This was traced to the

591 occurrence of large salt (notable sodium chloride) molecules. Therefore, it absorbed less water,

592 similar to that of normal water. Among the four environmental conditions, PLSF composite

593 immersed in normal water recorded the least value of water absorption. 


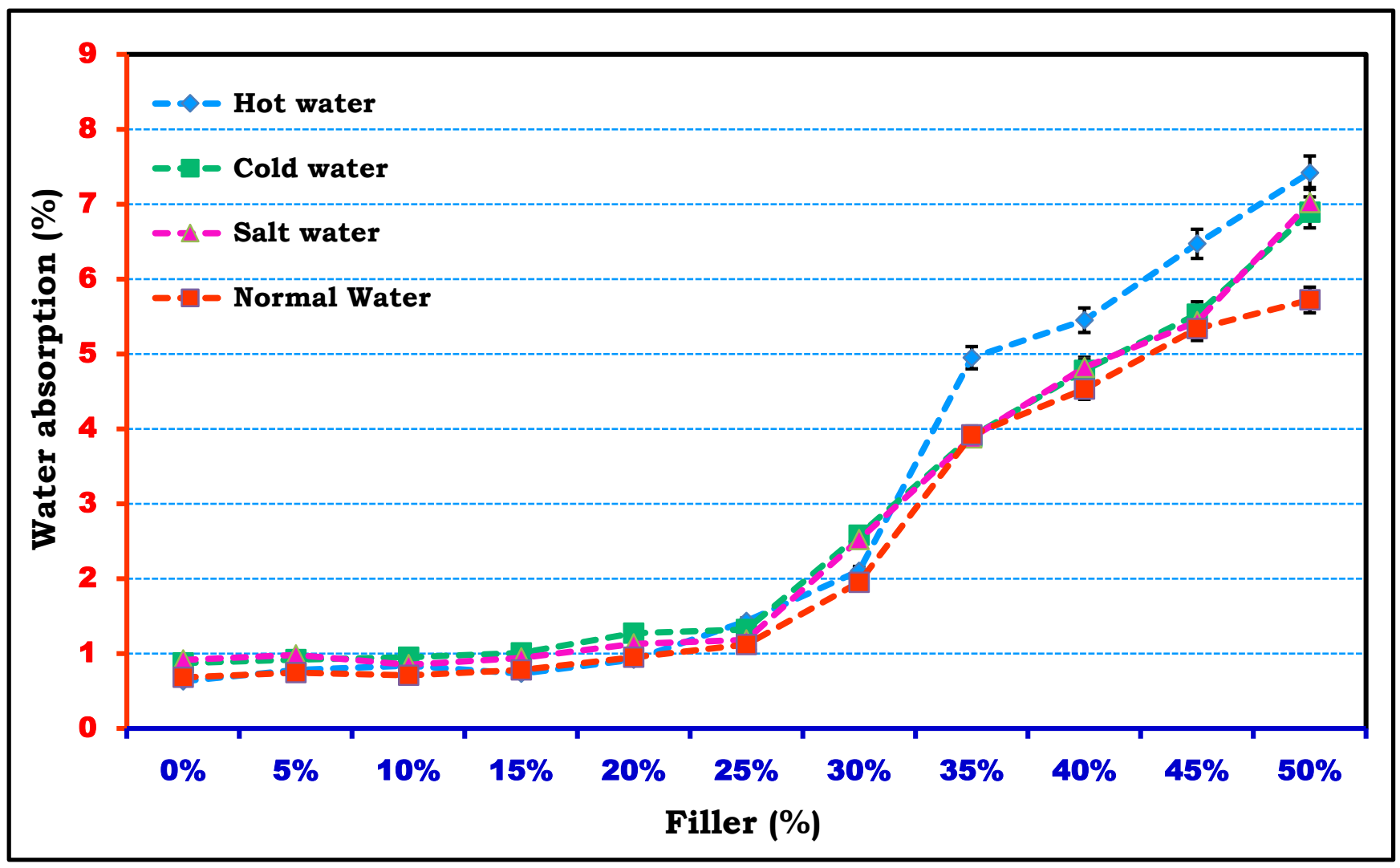

Fig. 9. Water absorption behaviors of the various samples under different aqueous

environments.

\section{Conclusions}

599 The characterization of Polyalthia longifolia seed bio-filler as well as mechanical, thermal and

600 water absorption behaviors of the PLSF/VE composite samples with varied filler loadings of 5

$601-50 \mathrm{wt} \%$ have been experimentally and extensively investigated. Therefore, the following 602 conclusions were drawn from the results obtained.

603 - The tensile strength of the PLSF-VE composite samples increased with the filler loadings 604 up to $30 \mathrm{wt} \%$, afterwards the tensile strength decreased, due to the poor interfacial 605 adhesion between the filler and matrix. This was evident from the SEM analysis. The 606 maximum tensile strength and modulus of the PLSF-VE composite were $32.50 \mathrm{MPa}$ and $607 \quad 1.23 \mathrm{GPa}$, respectively. 
- The flexural and impact strengths of the PLSF-VE samples were also extensively

609 influenced by the addition of filler, up to $35 \mathrm{wt} \%$. The flexural and impact strengths of the

610 PLSF-VE composites were increased by 1.60 and 2.63 times than that of neat vinyl ester

611 resin, respectively. The barcol hardness of the pure vinyl ester resin was 26.33 , but it

612 increased by $38.61 \%$ after adding PLS filler content of $25 \mathrm{wt} \%$.

613 - The thermal stability of the biocomposite sample was slightly enhanced by adding PLS

614 filler to the vinyl ester resin.

615 - Moreover, the water absorption test results indicated that the percentage of water 616 absorption followed a similar trend and was less in all the four environments considered 617 or water treatments, up to $25 \mathrm{wt} \%$ filler loadings. This was attributed to the existence of a 618 better filler-matrix interfacial bonding when compared with other filler loadings, 619 especially those with higher values.

620 - Summarily, it was evident that the optimum values from the investigated mechanical, 621 thermal and water absorption behaviors of the PLSF-VE composite samples occurred with 622 filler loading of $25 \mathrm{wt} \%$.

623

624

625

626

627

628

629

630

\section{Acknowledgements}

We hereby acknowledge and sincerely appreciate unalloyed supports from the managements of the following institutions: ULTRA College of Engineering and Technology, Anna University, Regional Campus Madurai as well as the Sethu Institute of Technology, Tamil Nadu, India. 


\section{References}

632 Abhishek, S., Sanjay, M. R., George, R., Siengchin, S., Parameswaranpillai, J., \& Pruncu, C. I. (2018). Development of new hybrid Phoenix pusilla/carbon/fish bone filler reinforced polymer composites. Journal of the Chinese Advanced Materials Society, 6(4), 553-560.

Akil, H. M., Cheng, L. W., Ishak, Z. A. M., Bakar, A. A., \& Rahman, M. A. A. (2009). Water absorption study on pultruded jute fibre reinforced unsaturated polyester composites. Composites Science and Technology, 69(11-12), 1942-1948.

638

Adeosun, S. O., Gbenebor, O, P., Akpan, E. I., \& Udeme, F. A. (2016). Influence of organic fillers on physicochemical and mechanical properties of unsaturated polyester composites. Arabian Journal for Science and Engineering, 41(10), 4153-4159.

Balaji, A. N., Karthikeyan, M. K. V, \& Vignesh, V. (2016). Characterization of new natural 642 cellulosic fiber from kusha grass. International Journal of Polymer Analysis and Characterization, 21(7), 599-605.

644

Battegazzore, D., Noori, A., \& Frache, A. (2019). Natural wastes as particle filler for poly (lactic acid)-based composites. Journal of Composite Materials, 53(6), 783-797.

Bensalah, H., Gueraoui, K., Essabir, H., Rodrigue, D., Bouhfid, R., \& Qaiss, A. el kacem. (2017). Mechanical, thermal, and rheological properties of polypropylene hybrid

Conrad, C. M., 1944. Determination of wax in cotton fiber, a new alcohol extraction method. Industrial and Engineering Chemistry Analytical Edition, 16, 745-748.

Dixit, P., Mishra, T., Pal, M., Rana, T. S., \& Upreti, D. K. (2014). Polyalthia longifolia and its 652 pharmacological activities. International Journal of Scientific and Innovative Research, 2(1), 17-25.

654 Erdogan, S., \& Huner, U. (2018). Physical and mechanical properties of PP composites based on different types of lignocellulosic fillers. Journal of Wuhan University of Technology- 
657 Erkliğ, A., Alsaadi, M., \& Bulut, M. (2016). A comparative study on industrial waste fillers affecting mechanical properties of polymer-matrix composites. Materials Research Express, 3(10), 105302.

660 Gangil, B., Patnaik, A., \& Kumar, A. (2013). Mechanical and wear behavior of vinyl estercarbon/cement by-pass dust particulate filled homogeneous and their functionally graded composites. Science and Engineering of Composite Materials, 20(2), 105-116.

663

Gopinath, R., Ganesan, K., Saravanakumar, S. S., \& Poopathi, R. (2016). Characterization of new cellulosic fiber from the stem of Sida rhombifolia. International Journal of Polymer Analysis and Characterization, 21(2), 123-129.

Gupta, G., Gupta, A., Dhanola, A., \& Raturi, A. (2016). Mechanical behavior of glass fiber polyester hybrid composite filled with natural fillers. IOP Conference Series: Materials Science and Engineering, 149(1), 012091.

Karthikeyan, M. K. V., Balaji, A. N., \& Vignesh, V. (2016). Effect of rope mat and random orientation on mechanical and thermal properties of banana ribbon-reinforced polyester composites and its application. International Journal of Polymer Analysis and Characterization, 21, 296-304.

Kommula, V. P., Reddy, K. O., Shukla, M., Marwala, T., \& Rajulu, A. V. (2014). Mechanical properties, water absorption, and chemical resistance of Napier grass fiber strandreinforced epoxy resin composites. International Journal of Polymer Analysis and

Kumar, R., Kumar, K., \& Bhowmik, S. (2018). Mechanical characterization and quantification of tensile, fracture and viscoelastic characteristics of wood filler reinforced epoxy composite. Wood Science and Technology, 52(3), 677-699.

680 Montanes, N., Garcia-Sanoguera, D., Segui, V. J., Fenollar, O., \& Boronat, T. (2018). 
681

682

683

684

685

686

687

688

689

690

691

692

693

694

695

696

697

698

699

700

701

702

703

704

705

Processing and characterization of environmentally friendly composites from biobased polyethylene and natural fillers from thyme herbs. Journal of Polymers and the Environment, 26(3), 1218-1230.

Mayandi, K., Rajini, N., Pitchipoo, P., Sreenivasan, V.S., Jappes, J. T. W., \& Alavudeen, A. (2015). A comparative study on characterisation of Cissus quadrangularis and Phoenix reclinata natural fibers. Journal of Reinforced Plastics and Composites, 34(4), 269-280.

Najafi, S. K., Kiaefar, A., Hamidina, E., \& Tajvidi, M. (2007). Water absorption behavior of composites from sawdust and recycled plastics. Journal of Reinforced Plastics and Composites, 26(3), 341-348.

Nagaprasad, N., Stalin, B., Vignesh, V., Ravichandran, M., Rajini, N., \& Ismail, O. (2020). Effect of cellulosic filler loading on mechanical and thermal properties of date palm seed / vinyl ester composites. International Journal of Biological Macromolecules, 147, 5366.

Nagarajan, K. J., \& Balaji, A. N. (2016). Extraction and characterization of alkali-treated red coconut empty fruit bunch fiber. International Journal of Polymer Analysis and Characterization, 21(5), 387-395.

Nagarajan, K. J., Balaji, A. N., Rajan, S. T. K., \& Ramanujam, N. R. (2020). Preparation of bio-eco based cellulose nanomaterials from used disposal paper cups through citric acid hydrolysis. Carbohydrate Polymers, 235, 115997.

Owen, M. M., Ogunleye, C. O., \& Achukwu, E. O. (2015). Mechanical properties of sisal fibrereinforced epoxy composites-effect of alkali concentrations. Advanced Polymer Science and Technolgy, 5, 26-31.

Pillai, G. P., Manimaran, P., \& Vignesh, V. (2020). Physico-chemical and mechanical properties of alkali-treated red banana peduncle fiber. Journal of Natural Fiber, doi:10.1080/15440478.2020.1723777. 
Pongdong, W., Kummerlöwe, C., Vennemann, N., Thitithammawong, A., \& Nakason, C. (2018). A comparative study of rice husk ash and siliceous earth as reinforcing fillers in epoxidized natural rubber composites. Polymer Composites, 39(2), 414-426.

Rao, R. A. K., \& Rehman, F. (2012). Use of Polyalthia longifolia seeds (seeds of Indian Mast tree) as adsorbent for the removal of Cd(II) from aqueous solution. Journal of Dispersion Science and Technology, 33(4), 472-481.

Razali, N., Sapuan, S. M., \& Razali, N. (2018). Mechanical properties and morphological analysis of Roselle/sugar palm fiber reinforced vinyl ester hybrid composites. In Natural fibre reinforced vinyl ester and vinyl polymer composites (pp. 169-180). Elsevier.

Richard, S., Rajadurai, J. S., \& Manikandan, V. (2016). Influence of particle size and particle loading on mechanical and dielectric properties of biochar particulate-reinforced polymer nanocomposites. International Journal of Polymer Analysis and Characterization, 21(6), $462-477$.

Richard, S., Selwin Rajadurai, J., Manikandan, V., Thanu, M. C., Arumugaprabu, V., \& Johnson, R. D. J. (2019). Study of tribological properties of nano-sized red mud particlereinforced polyester composites. Transactions of the Indian Institute of Metals, 72(9), $2417-2431$.

Sánchez-Acosta, D., Rodriguez-Uribe, A., Álvarez-Chávez, C. R., Mohanty, A. K., Misra, M., López-Cervantes, J., \& Madera-Santana, T. J. (2019). Physicochemical characterization and evaluation of pecan nutshell as biofiller in a matrix of poly (lactic acid). Journal of Polymers and the Environment, 27(3), 521-532.

Sathishkumar, T. P., Navaneethakrishnan, P., \& Shankar, S. (2012). Tensile and flexural properties of snake grass natural fiber reinforced isophthallic polyester composites. Composites Science and Technology, 72(10), 1183-1190.

Sreenivasan, V. S., Somasundaram, S., Ravindran, D., Manikandan, V., \& Narayanasamy, R. 

(2011). Microstructural, physico-chemical and mechanical characterisation of Sansevieria cylindrica fibres-An exploratory investigation. Materials \& Design, 32(1), 453-461.

Stalin, B., Nagaprasad, N., Vignesh, V., \& Ravichandran, M. (2019). Evaluation of mechanical and thermal properties of tamarind seed filler reinforced vinyl ester composites. Journal of Vinyl and Additive Technology, 25(s2), E114-E128.

Sutivisedsak, N., Cheng, H. N., Burks, C. S., Johnson, J. A., Siegel, J. P., Civerolo, E. L., \& Biswas, A. (2012). Use of nutshells as fillers in polymer composites. Journal of Polymers and the Environment, 20(2), 305-314.

Vaisakh, S. S., Peer Mohammed, A. A., Hassanzadeh, M., Tortorici, J. F., Metz, R., \& Ananthakumar, S. (2016). Effect of nano-modified $\mathrm{SiO}_{2} / \mathrm{Al}_{2} \mathrm{O}_{3}$ mixed-matrix microcomposite fillers on thermal, mechanical, and tribological properties of epoxy polymers. Polymers for Advanced Technologies, 27(7), 905-914.

Vignesh, V., Balaji, A. N., \& Karthikeyan, M. K. V. (2016). Extraction and characterization of new cellulosic fibers from Indian mallow stem: An exploratory investigation. International Journal of Polymer Analysis and Characterization, 21(6), 504-512.

Vignesh, V., Balaji, A. N., \& Karthikeyan, M. K. V. (2017). Effect of wood sawdust filler on the mechanical properties of Indian mallow fiber yarn mat reinforced with polyester composites. International Journal of Polymer Analysis and Characterization, 22(7), 610621.

Vigneshwaran, S., Uthayakumar, M., \& Arumugaprabu, V. (2019). Development and sustainability of industrial waste-based red mud hybrid composites. Journal of Cleaner Production, 230, 862-868.

Zheng, H., Sun, Z., \& Zhang, H. (2019). Effects of walnut shell powders on the morphology and the thermal and mechanical properties of poly (lactic acid). Journal of Thermoplastic Composite Materials, 20(10), 1-13. 